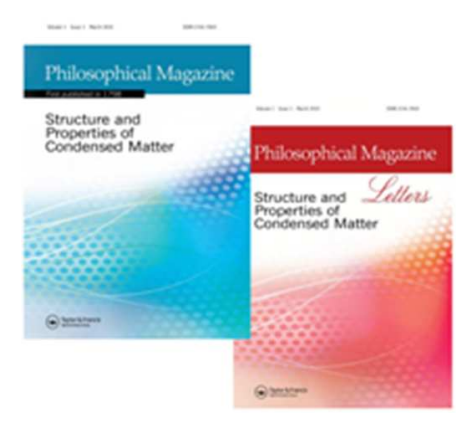

\title{
Positron annihilation study of the vacancy clusters in ODS Fe-14Cr alloys
}

\begin{tabular}{|r|l|}
\hline Journal: & Philosophical Magazine \& Philosophical Magazine Letters \\
\hline Manuscript ID & TPHM-16-Jan-0037 \\
\hline Journal Selection: & Philosophical Magazine \\
\hline Complete List of Authors: & $\begin{array}{l}\text { Domínguez-Reyes, Ricardo; Universidad Carlos III de Madrid, Physics } \\
\text { Auger, María; University of Oxford, Department of Materials; Universidad } \\
\text { Carlos III de Madrid, Physics } \\
\text { Monge, Miguel; Universidad Carlos III de Madrid, Physics } \\
\text { Pareja, Ramiro; Universidad Carlos III de Madrid, Physics }\end{array}$ \\
\hline Keywords: & positron annihilation, steel, alloys \\
\hline Keywords (user supplied): & ODS alloys, vacancy clusters \\
\hline &
\end{tabular}




\title{
Positron annihilation study of the vacancy clusters in ODS Fe-14Cr alloys
}

\author{
R. Domínguez-Reyes ${ }^{\mathrm{a}^{*}}$, M. A. Auger ${ }^{\mathrm{a}, \mathrm{b}}$, M. A. Monge ${ }^{\mathrm{a}}$ and R. Pareja ${ }^{\mathrm{a}}$ \\ ${ }^{a}$ Departamento de Física, Universidad Carlos III de Madrid, Avda. de la Universidad \\ 30. 28911 Leganés, Madrid, Spain. \\ ${ }^{b}$ Department of Materials, University of Oxford. OX1 3PH Oxford, UK. \\ * Corresponding author. E-mail address: rdomingu@fis.uc3m.es (R. Domínguez-Reyes)
}




\section{Positron annihilation study of the vacancy clusters in ODS Fe-14Cr alloys}

Oxide dispersion strengthened $\mathrm{Fe} 14 \mathrm{Cr}$ and $\mathrm{Fe} 14 \mathrm{CrWTi}$ alloys produced by mechanical alloying and hot isostatic pressing were subjected to isochronal annealing up to $1400{ }^{\circ} \mathrm{C}$, and the evolution and thermal stability of the vacancy type defects were investigated by positron annihilation spectroscopy. The results were compared to those from a non-oxide dispersion strengthened $\mathrm{Fe} 14 \mathrm{Cr}$ alloy produced by following the same powder metallurgy route. The long lifetime component of the positron annihilation spectra revealed the existence of tridimensional vacancy clusters, or nanovoids, in all these alloys. Two recovery stages are found in the oxide dispersion strengthened alloys irrespective of the starting conditions of the samples. The first one starting at $\mathrm{T}>750{ }^{\circ} \mathrm{C}$ is attributed to thermal shrinkage of large vacancy clusters, or voids. A strong increase in the intensity of the long lifetime after annealing at temperatures in the $800-1050{ }^{\circ} \mathrm{C}$ range indicates the development of new vacancy clusters. These defects appear to be unstable above $1050{ }^{\circ} \mathrm{C}$, but some of them remain at temperatures as high as $1400{ }^{\circ} \mathrm{C}$, at least for $90 \mathrm{~min}$.

Keywords: word; positron annihilation, steel, ODS alloys, vacancy clusters

\section{Introduction}

Dispersion strengthened ferritic Fe-Cr alloys with $\mathrm{Y}_{2} \mathrm{O}_{3}$ addition are presently considered one of the most promising structural materials for the future fusion reactors and generation IV fission reactors due to their enhanced high temperature strength, microstructural stability, radiation resistance, and good creep resistance at high temperature [1-4]. The appropriate powder metallurgy processing of these alloys develops a homogeneous dispersion of nano-sized hard particles that governs these mandatory properties. Analytical transmission electron microscopy (TEM) and atom probe tomography (APT) studies have contributed to reveal the dimensional, structural and compositional characteristics of the nanoparticles present in these alloys [5-9]. The 
fundamental elements of these nano-features are $\mathrm{O}, \mathrm{Y}$ and $\mathrm{Cr}$, and some alloying impurities intentionally or accidentally added such as $\mathrm{Ti}, \mathrm{Al}$ or $\mathrm{Si}$ [10-13], which appear to refine the size and increase the number density and stability of these nano-features. Experimental evidences for defective nanoclusters, or nano-features, in the ODS steel with a nominal composition Fe-14Cr-3.0W-0.4Ti-0.24Y2O3 (wt\%), denoted as 14YWTi, have been found from analytical and high resolution transmission electron microscopy (TEM) studies [8]. There are also positron annihilation spectroscopy (PAS) results that point out certain association between vacancy clusters, or nanovoids, and the oxide dispersion in ODS steels [14-16]. It should be noticed that there are PAS results showing vacancy clustering, as well the opposite, in non-ODS steels processed following a powder metallurgy (PM) route similar to the ODS ones, i.e. mechanical alloying (MA) and hot isostatic pressing (HIP) consolidation [14, 17]. It is the case of the non-ODS steels with nominal composition $\mathrm{Fe}-12 \mathrm{wt} \% \mathrm{Cr}$ showing no evidence of tridimensional vacancy clusters in the as-HIP condition, but these clusters were detected after a heat treatment at $850^{\circ} \mathrm{C}$ [17]. These results suggest that the designedly addition of solutes such as Y and Ti would not be the decisive factors for vacancy clustering associated to the oxide nano-features in the ODS steels but the processing conditions and the thermal history of the alloy.

To evidence the above and provide a better understanding on the role of the vacancies in the formation of nano-features in the ODS steels, and on the vacancy cluster behavior, a series of comprehensive isochronal annealing experiments and PAS measurements have been accomplished in ODS Fe14Cr alloys, with and without (W+Ti) addition, and in the counterpart non-ODS Fe14Cr alloy. PAS is a successful technique to study vacancy-type defects in metals and alloys [18]. Lattice defects such as vacancies, voids, solute-vacancy complexes and other open-volume defects are 
effective traps for thermalized positrons in a solid. When a positron annihilates trapped in a defect, the annihilation radiation conveys information about the defect. The positron lifetime distribution provides information on the type, size and concentration of the defects. In addition, the Doppler broadening of the annihilation radiation peak at 511 $\mathrm{keV}$, which depends on the momentum of the electrons annihilating with the thermalized positrons, can give information about the chemical surround of the positron annihilation sites $[19,20]$. Thus, the concurrent positron lifetime spectroscopy (PLS) and coincidence Doppler broadening (CDB) measurements in isochronally annealed samples would contribute to assess the recovery kinetics of the vacancy defects and their stability in relation with the solute impurities in the ODS alloys. The understanding and assessment of these subjects are of prime interest for developing irradiation-resistant and high-temperature alloys for structural applications. The stability and recovery of radiation-induced defects would be associated with the inherent vacancy-type defects and nano-features present in the ODS alloys, as these can act as strong sinks for lattice defects induced by radiation. The results would contribute to predict the stability of the nano-featured ODS Fe-Cr alloys under the working conditions.

\section{Experimental}

ODS alloys with target compositions: Fe-14Cr- $0.3 \mathrm{Y}_{2} \mathrm{O}_{3}$ (wt \%), Fe-14Cr-2W-0.3Ti-0.3 $\mathrm{Y}_{2} \mathrm{O}_{3}(\mathrm{wt} \%)$ and Fe-14Cr-2W-0.3Ti-0.24Y (wt \%), and a non-ODS Fe-14Cr alloy (wt $\%$ ), were processed by a PM route consisting of MA and consolidation by HIP for $2 \mathrm{~h}$ at $1100{ }^{\circ} \mathrm{C}$ and $200 \mathrm{MPa}$. These alloys are hereafter denoted as Fe14CrY, Fe14CrYWTi, Fe14CrWTiY and Fe14Cr, respectively. The processing details are found elsewhere [21-23]. The consolidated billets of Fe14CrY, Fe14CrYWTi and Fe14Cr $(\sim 30 \mathrm{~mm} \varnothing$ 
$\times 55 \mathrm{~mm}$ ) were forged between 1050 and $1150^{\circ} \mathrm{C}$ into the form of $\sim 12 \times 12 \times 170 \mathrm{~mm}$ bars, and afterwards heat treated for $2 \mathrm{~h}$ at $850^{\circ} \mathrm{C}$ and air cooled. The Fe14CrWTiY alloy was not forged but heat treated for $1 \mathrm{~h}$ at $1300^{\circ} \mathrm{C}$. Sample pairs with dimensions $10 \times 10 \times 1 \mathrm{~mm}$ were cut by electro-erosion from the ingots, and then their surfaces mechanically polished to a mirror finishing using alumina slurry. The PAS experiments were performed on sample pairs after successive isochronal annealing for $90 \mathrm{~min}$ from room temperature and up to $1400^{\circ} \mathrm{C}$ in $100^{\circ} \mathrm{C}$ steps in a vacuum pressure $<10^{-5}$ mbar. The isochronal annealing experiments in the $\mathrm{Fe} 14 \mathrm{CrY}$ alloy were performed on three pairs of samples with different starting conditions: as-HIP, as-forged, and heat treated at $850^{\circ} \mathrm{C}$ after forging. The starting condition for the Fe14CrYWTi and Fe14Cr alloys was the thermal treatment at $850^{\circ} \mathrm{C}$ after forging, and for the Fe14CrWTiY alloy the thermal treatment at $1300^{\circ} \mathrm{C}$.

The positron annihilation experiments were carried out in a fast-fast coincidence spectrometer with a time resolution of 230 ps (FWHM) using a ${ }^{22} \mathrm{Na}$ source sealed in kapton sandwiched between the pair of samples. Positron lifetime spectra with a total count number $>10^{6}$ were properly fitted to a sum of two lifetime components, $\tau_{1}$ and $\tau_{2}$, after subtracting the corrections due to positron annihilation in the ${ }^{22} \mathrm{Na}$ source. These spectra are characterized by a mean positron lifetime defined as

$$
\langle\tau\rangle=\tau_{1} I_{1}+\tau_{2} I_{2}
$$

where $I_{1}$ and $I_{2}$ are intensities of the corresponding components. The instrumental time resolution and contribution of the positron source to the lifetime spectra were determined from measurements on reference samples of annealed pure Fe and Si single crystals. The PATFIT-88 package was used for fitting the spectra [24]. 
Coincidence Doppler broadening measurements were done using two HP Ge detectors in timing coincidence, placed face to face with the samples at the half-way point between the detectors. The resulting CDB spectrum was the cumulative spectrum of 24 CDB spectra without evidence of electronic shift, each of them with a count number $>10^{6}$ in a $512 \times 512$ coincidence matrix. The cumulative spectra had $1 \times 10^{7}$ counts in the strip centered on the matrix diagonal for the energy range $2 m_{0} c^{2}-1.6$ $\mathrm{keV}<E_{1}+E_{2}<2 m_{\mathrm{o}} c^{2}+1.6 \mathrm{keV} ; E_{1}$ and $E_{2}$ stand for the energies of the pair of annihilating photons, $m_{o}$ the electron rest mass and $c$ the light speed. The spectra were binned from 40 to 512 bins with a bin width of $2.5 \times 10^{-3} m_{o} c$ to decrease the statistical fluctuations of the data in the high momentum region. The spectra were then normalized and the intensity at a given photon momentum divided by the corresponding counts in the CDB spectrum of a reference sample in order to highlight the differences between the spectra. Pure annealed $\mathrm{Fe}$ and $\mathrm{Cr}$, and pure $\mathrm{Y}_{2} \mathrm{O}_{3}$ were used as reference samples. The fraction of positron annihilating with low- and high-momentum electrons was also measured using the $S$ and $W$ line shape parameters. The $S$ parameter was calculated as the ratio of the count number in the energy window of $1.946 \mathrm{keV}$ centered at $511 \mathrm{keV}$ to the count total in the annihilation peak. The $\mathrm{W}$ parameter was calculated as the fraction of counts in the energy interval $515.66-519.72 \mathrm{keV}$ and $502.67-506.74 \mathrm{keV}$.

\section{Results}

\subsection{Positron lifetime measurements}

The evolution of $\tau_{1}, \tau_{2},\langle\tau\rangle$ and $I_{2}$ as a function of annealing temperature is represented in Figures 1 and 2. All the alloys exhibited a two-component spectrum through the annealing temperature range except $\mathrm{Fe} 14 \mathrm{CrY}$ in the as-HIP condition, which yielded a single-component after annealing at $950{ }^{\circ} \mathrm{C}<\mathrm{T}<1350^{\circ} \mathrm{C}$, see Figure 1a). The lifetime 
value of the second component, $\tau_{2}$, for Fe $14 \mathrm{Cr}$ heat treated after forging decays monotonously from $\sim 480$ ps to $\sim 360$ ps through the temperature range, see Figure $2 \mathrm{c}$ ). In contrast, the ODS alloys presented a visible recovery of the $\tau_{2}$ value with onset at temperatures between 750 and $950{ }^{\circ} \mathrm{C}$, which seems to depend on the treatments underwent after their HIP consolidation as the plots represented in Figures 1 and 2 reveal. Up to the recovery temperature, the $\tau_{2}$ value remained essentially constant for these alloys except for $\mathrm{Fe} 14 \mathrm{CrY}$ in the as-forged condition. After annealing at $\mathrm{T}<950{ }^{\circ} \mathrm{C}$ the mean value of $\tau_{2}$ resulted in $(350 \pm 40)$ ps and $(293 \pm 24)$ ps for $\mathrm{Fe} 14 \mathrm{CrY}$ in the

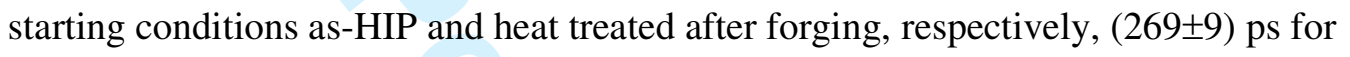
Fe14CrYWTi heat treated after forging and $(291 \pm 12)$ ps for heat treated Fe14CrWTiY. In order to emphasize the changes accompanying the recovery, the dispersion in the $I_{2}$ values was limited constraining $\tau_{2}$ to the mean value above quoted for the corresponding spectra. Short lifetime values, ranging between 110 and 200 ps in these alloys, may be attributed to positron annihilation at an abundant variety of defects inherent to their complex microstructure such as single vacancies, divacancies or trivacancies, impurityvacancy complex, dislocations or defects associated with them as jogs, vacancies and impurity-vacancy complexes, defects at grain boundaries and interfaces, as well as defects related with second-phase precipitates [14, 25, 26]. Positron lifetime values between 220 and 400 ps appear to be characteristic of annihilation in tridimensional vacancy clusters or nanovoids in $\alpha-F e$ [27-29].

In the interpretation of the lifetime results the following remarks have to be considered. 1) The fact that positron lifetime spectra are inconsistent with a standard trapping model derives from the complex microstructure of these alloys as revealed by TEM analyses $[22,23,30]$. The high number density and variety of complex defects, heterogeneously distributed in many cases, prevent any precise and reliable information 
about the defects contributing to the short lifetime component even though a diffusionlimited trapping model is applied. 2) Attempts for decomposing the short lifetime component in those spectra that exhibited a $\tau_{1}$ value as high as $\sim 200 \mathrm{ps}$, increasing the total number count of the spectra or constraining the lifetime values, failed. These analyses resulted in unrealistic lifetime values, or alternatively, either negative or meaningless intensity values with very large errors, and unacceptable variances. The above remarks point out that the second lifetime component that appears in the ODS alloys after annealing at $950{ }^{\circ} \mathrm{C}$ would be essentially attributable to real changes in the positron traps induced by annealing. Moreover, specific information about the positron traps responsible for the short lifetime component cannot be achieved from the present results. Nevertheless, the partial recovery or transformation of these traps can be inferred from the changes in the lifetime $\tau_{1}$ and intensity $\mathrm{I}_{1}=1-\mathrm{I}_{2}$.

\section{1a. $\mathrm{Fe} 14 \mathrm{CrY}$}

Figure 1 summarizes the effect of the thermo-mechanical treatment on the annihilation parameters for the ODS Fe14CrY alloy. The second lifetime of 350 ps, present in the as-HIP condition, disappears completely after annealing at temperatures in the interval $950^{\circ} \mathrm{C}<\mathrm{T}<1350{ }^{\circ} \mathrm{C}$ but a very strong second lifetime component of $\sim 250$ ps develops after annealing at $1350{ }^{\circ} \mathrm{C}$. This is observed along with a considerable reduction of the $\tau_{1}$ value, which indicates thermal activated vacancy release from defects contributing to the short lifetime component and formation of new open-volume defects. The evolution of $I_{2}$ indicates the recovery onset of vacancy-type defects at $750{ }^{\circ} \mathrm{C}$, which means that the defects responsible for the 350 ps component become unstable and start to release vacancies. These migrating vacancies appear to flow to strong vacancy sinks contributing to the short lifetime component, as its lifetime value rises from (195 \pm 2$)$ ps 
to $(220 \pm 1)$ ps up to developing tridimensional vacancy clusters that give rise to the observed second lifetime component of $\sim 250 \mathrm{ps}$.

The alloy in the as-forged condition exhibits an initial second lifetime component of 260 ps with a much higher intensity $I_{2}$ than the one for the alloy in the asHIP condition, $28 \%$ against $1.2 \%$, see the corresponding plots in Figure 1. After annealing at $150{ }^{\circ} \mathrm{C}, I_{2}$ goes down to $9 \%$ and $\tau_{2}$ increases to $\sim 400 \mathrm{ps}$. These values remain practically constant after the successive anneals up to $750{ }^{\circ} \mathrm{C}$. This indicates that a significant part of the defects responsible for this 260 ps component being smaller in size and very much abundant than those of $350 \mathrm{ps}$ in the as-HIP samples are unstable at $150^{\circ} \mathrm{C}$. It should be noted that the forged material in the air-cooled condition may retain vacancies frozen as complex vacancy clusters. The vacancy release from these defects at $150^{\circ} \mathrm{C}$ appears to promote coarsening of other more stable defects, although in competition with other vacancy sinks. The latter may be some of the defects that contribute to the short lifetime as the simultaneous increment in $\tau_{1}$ and $I_{1}$ shows. At $\mathrm{T}>750{ }^{\circ} \mathrm{C}$ the $\tau_{2}$ and $\tau_{1}$ values start to recover simultaneously. This can be interpreted as dissolution of the large voids responsible for the $\sim 380$ ps component and trapping of the released vacancies in some of the defects contributing to short positron lifetime, which turn into tridimensional vacancy clusters, or nanovoids. These clusters with lifetime

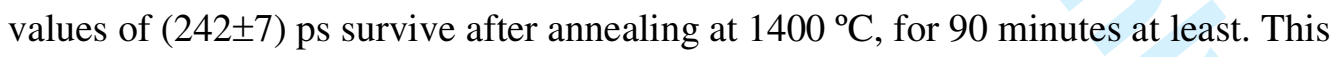
interpretation would be compatible with the fact that the $\langle\tau\rangle$ value is unaltered after the recovery of the 380 ps traps, see Figure 1b). As an alternative interpretation one can conceive that defects responsible for the lifetime of $\sim 240$ developed after annealing at $\mathrm{T}>750{ }^{\circ} \mathrm{C}$ were actually present before but contributing to the short lifetime component. Then, it would be resolved by the fits after annealing out the 380 ps defects. However, if 
the number density of the 240 ps defects is unchanged after annealing at $\mathrm{T}>750{ }^{\circ} \mathrm{C}$ the $\langle\tau\rangle$ value should very likely decrease instead of remaining essentially constant.

The unexpected large uncertainty in the $I_{2}$ value for the as-forged samples after the isochronal anneal at $850^{\circ} \mathrm{C}$, confirmed repeating the measurements at least 3 times, demanded attention, see Figure 1b). Thus, isothermal annealing experiments at $800{ }^{\circ} \mathrm{C}$ and $850^{\circ} \mathrm{C}$ were performed on a pair of samples starting from the as-forged and aircooled condition. The results are summarized in Table 1. After isothermal annealing for $30 \mathrm{~min}$ at $800{ }^{\circ} \mathrm{C}$ the second lifetime component yields $I_{2}$ and $\tau_{2}$ values of $(13 \pm 17) \%$ and $(265 \pm 50) \mathrm{ps}$, which remain essentially constant after isothermal annealing for 270 min. The subsequent isothermal annealing at $850^{\circ} \mathrm{C}$ for $30 \mathrm{~min}$ induces a remarkable increase in the $I_{2}$ value and in its uncertainty, as well as a reduction in $\tau_{2}$. Afterwards, the $I_{2}$ and $\tau_{2}$ values appear to be constant after annealing beyond $90 \mathrm{~min}$. It is worth noticing that the $\tau_{1}$ value remains constant after isothermal annealing at $800{ }^{\circ} \mathrm{C}$ longer than $30 \mathrm{~min}$, but it lowers remarkably after isothermal annealing at $850{ }^{\circ} \mathrm{C}$ and becomes again constant when the annealing time is above $90 \mathrm{~min}$. This appears to reproduce the $\tau_{1}$ behavior at the recovery onset of $\tau_{2}$ in the as-forged Fe14CrY samples isochronally annealed, as the corresponding plot in Figure 1b) and results in Table 1 show.

The evolution of $I_{2}$ for the Fe14CrY samples heat treated after forging exhibits an isochronal annealing behavior very similar to that for the samples in as-HIP condition, except for the vanishing of second lifetime component, as the comparison between the plots in Figure 1 reveals. After annealing at $1050{ }^{\circ} \mathrm{C}, I_{2}$ rises from 10 to 92 $\%$ accompanied by a drop in $\tau_{2}$ from $293 \pm 24$ to $218 \pm 3$ ps. At temperatures above 1050 ${ }^{\circ} \mathrm{C}, I_{2}$ decreases and $\tau_{2}$ increases, ending at values of $\sim 60 \%$ and $\sim 245 \mathrm{ps}$ after the final anneal at $1400^{\circ} \mathrm{C}$, in concordance with the corresponding values for the other two pairs of Fe14CrY samples. In the samples heat treated after forging it is worth noticing the 
clear correlation of the onset of the $I_{2}$ recovery at $750{ }^{\circ} \mathrm{C}$ with the rise of $\tau_{1}$, as well as the simultaneous correspondence between the maximum values of $I_{2}$ with the minimum $\tau_{1}$ values, as the plots in Figure 1c) show. This correspondence is also evident in the other two pair of samples although it occurs at different temperatures.

Regarding the evolution of the mean positron lifetime $\langle\tau\rangle$ with isochronal annealing no significant changes are observed for the samples in the as-HIP or as-forged conditions. For the samples heat treated after forging, $\langle\tau\rangle$ appears to slightly rise after annealing at $950{ }^{\circ} \mathrm{C}$ remaining constant until $1350{ }^{\circ} \mathrm{C}$, and then decreases just below the initial value.

\section{1b. Fe14CrYWTi and Fe14CrWTiY}

As stated in Section 2, the starting conditions for the samples of these two alloys were different: thermal treatment at $850^{\circ} \mathrm{C}$ after forging for Fe14CrYWTi and heat treatment at $1300{ }^{\circ} \mathrm{C}$ for Fe14CrWTiY. Nevertheless, either alloys exhibit decrease of the $I_{2}$ above $750^{\circ} \mathrm{C}$ accompanied by a rise of $\tau_{1}$ in the same way as the Fe14CrY alloy, see the plots in Figure 2. Afterwards, $\tau_{1}$ and $\tau_{2}$ recover in coincidence with a steeply increase in $I_{2}$ up to attaining a maximum value after annealing at $\sim 1150^{\circ} \mathrm{C}$. Beyond this temperature, $\tau_{1}$ and $\tau_{2}$ are practically constant and the mean lifetime $\langle\tau\rangle$ drops due to the decrease of the intensity $I_{2}$, which implies annealing out of the open volume defects responsible for the second lifetime component being more evident for Fe14CrYWTi.

\section{1c. $\mathrm{Fe} 14 \mathrm{Cr}$}

The recovery characteristics of this non-ODS alloy, heat treated at $850{ }^{\circ} \mathrm{C}$ after forging, differ noticeably from those observed for the ODS alloys. The lifetime $\tau_{2}$ does not exhibit the distinctive steep recovery of the ODS alloys at $800-1000{ }^{\circ} \mathrm{C}$ but a 
gradual reduction starting after annealing above $250{ }^{\circ} \mathrm{C}$ as the plots in Figures 1 and 2 reveal. Moreover, the recovery of $\langle\tau\rangle$ occurs at $1050^{\circ} \mathrm{C}$ corresponding with the continuous $I_{2}$ decrease and a constant $\tau_{1}$ value. Preceding this recovery, $I_{2}$ increases at the same time that the reduction in the $\tau_{1}$ value occurs for annealing above $750{ }^{\circ} \mathrm{C}$. This is also interpreted as evidence of vacancy release from defects contributing to the first lifetime component and subsequent formation of new voids like it occurs for the ODS alloys. In addition, it appears that $\mathrm{Fe} 14 \mathrm{Cr}$ heat treated after forging exhibits an initial $I_{2}$ decreases concurrently with a considerable increase of the $\tau_{2}$ value after annealing at $150^{\circ} \mathrm{C}$. This can be the result of vacancy release from unstable vacancy clusters and their competitive trapping in defects responsible for the first lifetime component, and in stable voids that grow.

\subsection{CDB measurements}

The characteristics of the ratio CDB curves and their evolution with isochronal annealing are shown for selected annealing temperatures in Figures 3 and 4, along with the ratio curves for the reference samples of the alloying elements and $\mathrm{Y}_{2} \mathrm{O}_{3}$. All the $\mathrm{CDB}$ curves at a given annealing temperature are normalized to the one for $\mathrm{Fe} 14 \mathrm{Cr}$ annealed at the corresponding temperature. No significant changes respect to the Fe14Cr samples are found in the low-momentum region, i.e. for $p_{L}<10 \times 10^{-3} m_{o} c$, after annealing at temperatures $\mathrm{T}<950^{\circ} \mathrm{C}$. In this region some changes are evident after annealing at $\mathrm{T} \geq 950^{\circ} \mathrm{C}$, except for the Fe14CrYWTi samples. By contrast, the annealing effect on the high-momentum side of the ratio curves of the ODS alloys is obvious. The remarkable reduction of the positron annihilations with high-momentum electrons, relative to the $\mathrm{Fe} 14 \mathrm{Cr}$ alloy, appears to be related to a major contribution of the core electrons of $\mathrm{Cr}$, or other alloying elements such as $\mathrm{Y}, \mathrm{W}$, Ti and $\mathrm{Si}$, in the annihilation 
events. Nevertheless, the effective changes over the high-momentum side appear not to follow a defined pattern revealing the characteristic signature of a particular alloying element. This result can be interpreted as evidence for competitive positron trapping in defects with a configurational surrounding that can either concurrently or separately contain $\mathrm{Cr}$, Y and other alloying impurities.

Figure 5 shows the $W-S$ correlation plots for all the samples. These plots are useful for revealing the presence of different positron traps or changes in the chemical surrounding of the positron annihilation sites during isochronal annealing. It is known in the case of positron annihilation taking place in two positron states, i.e. in a free state and in a trapped state in a single type of defect, or otherwise in two trapped state in two different types of defect, the measured line shape parameters $S$ and $W$ are given by [31]

$$
\begin{aligned}
& S=f_{1} S_{1}+\left(1-f_{1}\right) S_{2} \\
& W=f_{1} W_{1}+\left(1-f_{1}\right) W_{2}
\end{aligned}
$$

where $S_{\mathrm{i}}$ stand for the line shape parameters representative of the annihilations with the low momentum valence electrons for each state, and $W_{\mathrm{i}}$ the corresponding with the high momentum electrons. From Equation 2 the following correlation is found

$$
W=-R S+\left(W_{2}+R S_{2}\right)
$$

where $\mathrm{R}$ is a constant defect specific parameter independent of the number density of positron traps given by

$$
R=\frac{W_{1}-W_{2}}{S_{2}-S_{1}}=\frac{W-W_{2}}{S_{2}-S}
$$

and the measured values of $S$ and $W$ are in the range $S_{1}<S<S_{2}$ and $W_{2}<W<W_{1}$. Then, if the $W-S$ plot exhibits a full linear dependence, either a single type of defect acts 
as positron traps or there exists positron trapping saturation in two effective defects through the recovery and isochronal annealing. This is the case for non-ODS Fe14Cr, see the corresponding plot in Figure 5. In contrast, the plots for the ODS alloys only exhibit a linear dependence after annealing at $\mathrm{T}>1150{ }^{\circ} \mathrm{C}$ except for $\mathrm{Fe} 14 \mathrm{CrWTiY}$ heat treated at $1300{ }^{\circ} \mathrm{C}$.

\section{Discussion}

\section{1. $\mathrm{Fe} 14 \mathrm{CrY}$}

\section{1a. As-forged samples}

Among the different samples investigated, it is expected that the ODS Fe14Cr samples in the as-forged condition achieve the most far out of equilibrium microstructure because of the fast cooling rate after forging at $1100{ }^{\circ} \mathrm{C}$. The large increase of $\tau_{2}$ simultaneously with the significant drop of $I_{2}$ after annealing at $150{ }^{\circ} \mathrm{C}$ reveals thermal shrinking of metastable vacancy clusters and coarsening of stable ones via trapping of migrating vacancies. These large tridimensional clusters or voids are thermally stable up to $750^{\circ} \mathrm{C}$. Above this temperature these voids become unstable, the representative positron lifetime $\tau_{2}$ for the voids drops steeply and the intensity $I_{2}$ rises simultaneously, see Figure 1b). This can only be interpreted as a sign of development of new vacancy clusters at the expenses of the vacancies released from unstable voids during their thermal shrinkage. The characteristic $\tau_{2}$ value for the new clusters results to be $235 \pm 10$ ps after annealing at $\mathrm{T} \geq 950^{\circ} \mathrm{C}$. The fact that the $W$-S plot for these samples exhibits a constant $R$ value of $0.2330 \pm 0.0010$ for annealing temperatures $\mathrm{T}>1150{ }^{\circ} \mathrm{C}$ concurrent with the constant value of $\tau_{2}$ supports the above interpretation. These clusters, as well as those appearing in the temperature range $150-750^{\circ} \mathrm{C}$, must be associated with some 
solute impurities that stabilize them in the corresponding temperature range. According with the calculi of the positron lifetime for tridimensional vacancy clusters in pure $\alpha$-Fe, these clusters could contain a number of 3 to 5 vacancies if solute impurities are not found associated with them $[25,26]$, but they would be unstable at $150{ }^{\circ} \mathrm{C}$ [22]. Some impurities would therefore have to be associated with the stable vacancy clusters. Hence, the binding of solute atoms to these clusters would be reflected on the highmomentum region of the $\mathrm{CDB}$ spectrum by the contribution of core electrons from the solute atoms. After any annealing step, the high-momentum region of the CDB curves for $\mathrm{Fe} 14 \mathrm{CrY}$ in the as-forged condition seems to exhibit characteristics compatible with both the $\mathrm{Cr}$ and $\mathrm{Y}$ signature, see Figure 3. No conclusive evidence for the association of vacancy clusters with an exclusive atom, i.e. either $\mathrm{Cr}$ or $\mathrm{Y}$ atoms, can be attained from these curves. Thus, the changes in the high-momentum region induced by successive isochronal annealing can be interpreted as the result of the concurrent contribution of core electrons from $\mathrm{Cr}$ and $\mathrm{Y}$ atoms associated with the positron traps.

\section{1b. Heat-treated samples after forging}

The effect of the heat treatment at $850^{\circ} \mathrm{C}$ after forging is to shift the edge of the abrupt changes in $I_{2}, \tau_{2}$ and $\tau_{1}$ from $750{ }^{\circ} \mathrm{C}$ to $950{ }^{\circ} \mathrm{C}$, see Fig 1c). Nevertheless, these changes are preceded by a recovery of $I_{2}$ and a rise of $\tau_{1}$ indicating that: 1) some unstable vacancy clusters still remain after the pre-treatment at $850^{\circ} \mathrm{C}$ for $2 \mathrm{~h}$, and 2) there exists a flow of the vacancies released from the shrinking clusters to some defects that contributes to the first lifetime component, as occurs for the samples annealed in the asforged condition. These defects would have capability for trapping vacancies giving rise to a variety of positron traps apparently stable at $1050{ }^{\circ} \mathrm{C}$. Above this temperature, $I_{2}$ decreases rapidly with a simultaneous increase of $\tau_{2}$, which suggests shrinkage of some 
clusters and coarsening of others. However, the last anneal at $1400{ }^{\circ} \mathrm{C}$ lowers considerably the $\tau_{2}, \tau_{1}$ and $\langle\tau\rangle$ values revealing unstability of the defects, see Figure 1c). In these samples the linear correlation between the parameters $W$ and $S$ is also apparent after annealing at $\mathrm{T}>1150{ }^{\circ} \mathrm{C}$ with a parameter $\mathrm{R}$ of $0.2590 \pm 0.0021$ as the corresponding plot in Figure 5 reveals. For annealing at $\mathrm{T} \leq 1150{ }^{\circ} \mathrm{C}$ the $\mathrm{W}$ and $\mathrm{S}$ values are found apparently randomly distributed in a bound region suggesting a complex annihilation scheme in the samples with positron annihilations in more than two states. In contrast, this concentration of the $W$ and $S$ values does not occur for the as-forged samples. This difference in the evolution of the parameters $W$ and $S$ can be attributed to the pre-treatment at $850^{\circ} \mathrm{C}$.

The comparison of the ratio CDB spectra with those for the as-forged samples reveals that the fast recovery of $I_{2}$ after annealing at $\mathrm{T}>1150{ }^{\circ} \mathrm{C}$ is related to a considerable reduction of the $\mathrm{Cr}$ and $\mathrm{Y}$ contribution to high-momentum annihilations, see Figure 3 . The above and the fact that the defects induced by annealing at $1050^{\circ} \mathrm{C}$ are clearly unstable at higher temperatures in the heat treated samples, in parallel with the significant drop of $\langle\tau\rangle$ after annealing at $1400^{\circ} \mathrm{C}$, would indicate a relationship between the thermal stability of the defects and the presence of $\mathrm{Y}$ and $\mathrm{Cr}$ atoms in their surroundings.

\section{1c. As-HIP samples}

These samples through isochronal annealing at $\mathrm{T} \leq 950{ }^{\circ} \mathrm{C}$ replicate the evolution of the positron lifetime parameters observed in the samples heat treated after forging, see Figure 1 . Now, $I_{2}$ for $\mathrm{T} \leq 950{ }^{\circ} \mathrm{C}$ is considerably smaller, and $\tau_{2}$ and $\tau_{1}$ larger, than the corresponding values for the samples heat treated after forging. However, it is worth to notice that in any case the $\langle\tau\rangle$ values for the Fe14CrY alloy coincide just at the starting 
of the isochronal annealing experiments irrespective of the previous thermo-mechanical treatment. This result reveals that the HIP consolidated ODS Fe14Cr alloy contains an effective concentration of positron traps high enough to attain trapping saturation despite the subsequent treatments herein applied.

At temperatures above $950{ }^{\circ} \mathrm{C}$, the vacancy clusters responsible for the lifetime component of 350 ps anneal out, and a single lifetime component emerges gradually increasing its lifetime up to a value of $220 \pm 1 \mathrm{ps}$ upon annealing at $1250^{\circ} \mathrm{C}$. It is worth to be aware that the lifetime of the vacancy clusters growing after annealing at $1050{ }^{\circ} \mathrm{C}$ is $218 \pm 3$ ps in the samples heat-treated after forging and $221 \pm 3$ in the as-forged samples. Then, the single lifetime component of 220 ps appears to be due to positron annihilation saturation in the vacancy clusters grown by annealing, which coarsen at $\mathrm{T}>1250{ }^{\circ} \mathrm{C}$ while their concentration declines as the plot in Figure 1a) reflects. This interpretation is supported by the corresponding $W-S$ plots in Figure 5. Now, in opposition to that occurring for the other two Fe14CrY samples the lineal $W$ dependence on $S$ for $\mathrm{T}>1150{ }^{\circ} \mathrm{C}$ is decreasing with annealing temperature resulting in a defect specific parameter $\mathrm{R}$ of $0.349 \pm 0.019$. Furthermore, the random evolution of the data points through isochronal annealing at $\mathrm{T} \leq 1150^{\circ} \mathrm{C}$ reflects a starting defect structure in these samples that differs from those in the other two pair samples thermomechanically treated.

\subsection{Fe14CrYWTi heat-treated samples after forging}

The evolution of the lifetime parameters with isochronal annealing for these samples exhibits significant coincidences with the ODS Fe14Cr samples submitted to the same thermo-mechanical treatment as the respective plots in Figures 1c) and 2a) reveal. These are: 1) the $I_{2}$ recovery onset above $750{ }^{\circ} \mathrm{C}$ and simultaneous increase of $\tau_{1}$, and 2) the 
development of new vacancy clusters at $\mathrm{T}>950{ }^{\circ} \mathrm{C}$ revealed by the abrupt rise of $I_{2}$ concurrently with a considerable drop in $\tau_{1}$ and $\tau_{2}$. By contrast, there exist evident differences: 1) at $\mathrm{T}>1150{ }^{\circ} \mathrm{C}$, a remarkable recovery of the mean positron lifetime $\langle\tau\rangle$ appears with its onset at $1150{ }^{\circ} \mathrm{C}$ while the $\tau_{1}$ and $\tau_{2}$ values remain practically constant; and 2) at $\mathrm{T}<1050^{\circ} \mathrm{C}$, the second lifetime component due to vacancy clusters yield $I_{2}$ values at least $\sim 2.5$ times higher than those for the Fe14CrY samples, and $\tau_{2}$ values considerably smaller, i.e. 270 ps against 292 ps. These noteworthy differences respect to the counterpart Fe14CrY samples can only be attributed to the $\mathrm{W}$ and $\mathrm{Ti}$ addition. Nevertheless, a linear relationship between $W$ and $S$ like the one for the $\mathrm{Fe} 14 \mathrm{CrY}$ samples is satisfied after annealing at $\mathrm{T}>1150^{\circ} \mathrm{C}$ with a parameter $\mathrm{R}=0.322 \pm 0.006$, see the plots in Figure 5. For annealing a $\mathrm{T} \leq 1150^{\circ} \mathrm{C}$ the parameters $W$ and $S$ are found bounded inside an interval of values even narrower than the one for the counterpart pair of Fe14CrY samples being also attributable to the effect of the heat treatment at $850{ }^{\circ} \mathrm{C}$ after forging. As the $I_{2}$ value scales with the number concentration of the vacancy-type defects responsible for this lifetime component, and $\tau_{2}$ does it with the size, the positron lifetime results indicate that either $\mathrm{W}$ or Ti promotes the formation and refinement of the vacancy clusters. Since TEM studies of ODS Fe14CrWTi have revealed the capability of Ti for improving the dispersion of oxide particle via its incorporation into the oxide particle [32], the aforementioned differences should accordingly be associated with the Ti effect on the dispersion.

\subsection{Fe14CrWTiY heat-treated at $1300^{\circ} \mathrm{C}$}

The changes in the lifetime parameters for these samples are qualitatively similar to those found in Fe14CrYWTi as the plots in Figure 2 show, even though the respective pre-treatments were very different. A small recovery stage of $\mathrm{I}_{2}$ at $\mathrm{T}>750{ }^{\circ} \mathrm{C}$ followed 
by a strong rise of $I_{2}$, and a second recovery at $\mathrm{T}>1150{ }^{\circ} \mathrm{C}$ appear, which are accompanied by qualitative changes in $\tau_{2}, \tau_{1}$ and $\langle\tau\rangle$ similar to those observed in the Fe14CrYWTi samples. The fact that the $I_{2}$ values after annealing at $\mathrm{T} \leq 750{ }^{\circ} \mathrm{C}$ are a factor of $\sim 1.5$ to 2 smaller than the ones for Fe14CrYWTi may be attributed to annealing induced by the pre-treatment at $1300^{\circ} \mathrm{C}$ for $1 \mathrm{~h}$. But, it should be noted that after the final isochronal anneals at $1350{ }^{\circ} \mathrm{C}$ and $1400{ }^{\circ} \mathrm{C}$, which were longer in time than the pre-treatment for Fe14CrYWTi, $I_{2}$ and $\langle\tau\rangle$ for Fe14CrWTiY stay at values significantly higher than those for Fe14CrYWTi, i.e. $50 \%$ and 200 ps against $40 \%$ and 170 ps. This result is compatible with a possible presence of defects more stable than the ones present in Fe14CrYTiW. This possibility is supported by the TEM analyses accomplished in these samples that evidence a clear effect of the unintentional $\mathrm{Si}$ impurities on the oxide dispersion characteristics developed [21]. It was found that complex Y-Si oxide nanoparticles developed predominantly instead of Y-Ti oxide dispersoids. In that case, the high stability of vacancy clusters in these samples might be attributed to their association with the Y-Si oxide dispersoids or Si solutes.

The $W-S$ plot for Fe14CrWTiY exhibits a clear difference respect to those for the other ODS alloys, see Figure 5. The transition to a linear correlation between $W$ and $S$ after annealing at $\mathrm{T}>1150{ }^{\circ} \mathrm{C}$ is no longer evident, being very likely attributable to the pre-treatment at $1300^{\circ} \mathrm{C}$. As a result the $W$ and $S$ values appear not to be correlated with the annealing temperature over the whole temperature range. This means that the nano-features resulting in these samples is more complex than those for the other ODS alloys, which could be attributed to the effect of Si impurities present in these samples according with the above discussion. As occurs in the Fe14CrY alloy, the ratio CDB spectra shown in Figure 4 do not exhibit any clear sign attributable to any of the alloying impurities over the whole range of annealing temperature. The ratio CDB 
curves for reference samples of $\mathrm{Si}$ is also represented in Figure 4 to assess the $\mathrm{Si}$ effect on the enhanced stability of the vacancy clusters in the Fe14CrWTiY alloy unintentionally contaminated with Si. Moreover, the shape and evolution of the highmomentum side of the spectra being quite similar to the ones for Fe14CrY suggest a minor participation of the core electrons from $\mathrm{W}, \mathrm{Ti}$ and $\mathrm{Si}$ in the positron annihilations. At present, a consistent explanation of the enhanced stability of the vacancy defects developed in the Fe14CrWTiY samples cannot be given except that it is likely due to the thermo-mechanical treatments underwent by the samples.

\section{Conclusions}

Positron annihilation measurements were performed on samples of the ODS Fe14Cr and Fe14CrWTi alloys submitted to sequential isochronal annealing. The main findings are summarized as follows:

(1) Irrespective of the starting conditions of the samples, the results revealed the presence of tridimensional vacancy clusters, or defect nano-features, some of which can survive annealing at $1400^{\circ} \mathrm{C}$ for $90 \mathrm{~min}$, at least.

(2) The evolution of the positron annihilation characteristics shows two recovery stages for these vacancy type defects. The first one starting at $\mathrm{T}>750{ }^{\circ} \mathrm{C}$ is attributed to thermal shrinkage of large vacancy clusters, or voids, and consequent trapping of the released vacancies by other defects of different nature.

(3) Annealing in the temperature interval $800<\mathrm{T} \leq 1050^{\circ} \mathrm{C}$ gives rise to new vacancy clusters, whose number concentration is considerably higher than the one for the vacancy clusters existing at $\mathrm{T} \leq 750^{\circ} \mathrm{C}$. The new vacancy clusters start to anneal out at $\mathrm{T}>1050{ }^{\circ} \mathrm{C}$ in the $\mathrm{Fe} 14 \mathrm{CrY}$ samples and at $\mathrm{T}>1150^{\circ} \mathrm{C}$ in $\mathrm{Fe} 14 \mathrm{CrYWTi}$ 
and Fe14CrWTiY. In the case of the Fe14CrY samples isochronally annealed starting from the as-forged condition, the new clusters appear to exhibit the highest thermal stability.

(4) The number concentration of the vacancy clusters present in the Fe14CrYWTi samples after annealing at $\mathrm{T} \leq 750{ }^{\circ} \mathrm{C}$ is considerable higher, and their size smaller, compared with the corresponding ones in the Fe14CrWTiY samples. However, the major part of vacancy defects developed upon annealing at 950 ${ }^{\circ} \mathrm{C}$ result to be remarkably more stable in Fe14CrWTiY than in Fe14CrYWTi.

(5) The W-S plots for the ODS Fe14Cr and Fe14CrYWTi alloys reveal a clear transition in the relationship between these parameters after annealing at temperatures above $1050^{\circ} \mathrm{C}$. This is compatible with a change in the structure of the nano-features present in these alloys. This transition is not present in nonODS Fe14Cr alloys or in the case of the ODS Fe14CrWTiY alloy pre-heated at $1300{ }^{\circ} \mathrm{C}$.

\section{Acknowledgments}

This investigation was supported by the Spanish Ministry of Economy and Competitiveness (project ENE2012-39787-C06-05), Comunidad de Madrid (Spain) through the MULTIMATCHALLENGE (S2013/MIT-2862) and TECHNOFUSION (II)-CM (S2013/MAE2745) programs, and European Commission through the European Fusion Development Agreement (contracts 09-240 and 10-425).

\section{References}

[1] S. Ukai, and M. Fujiwara, J Nucl Mater, 307 (2002) 749-757.

[2] L.K. Mansur, A.F. Rowcliffe, R.K. Nanstad, S.J. Zinkle, W.R. Corwin, and R.E. Stoller, J Nucl Mater, 329 (2004) pp. 166-172.

[3] K.L. Murty, and I. Charit, J Nucl Mater, 383 (2008) pp. 189-195. 
[4] G.R. Odette, M.J. Alinger, and B.D. Wirth, Annu Rev Mater Res, 38 (2008) pp. 471-503.

[5] D.J. Larson, P.J. Maziasz, I.S. Kim, and K. Miyahara, Scripta Mater, 44 (2001) pp. 359-364.

[6] V. de Castro, E.A. Marquis, S. Lozano-Perez, R. Pareja, and M.L. Jenkins, Acta Mater, 59 (2011) pp. 3927-3936.

[7] M.K. Miller, and C.M. Parish, Mater Sci Tech-Lond, 27 (2011) pp. 729-734.

[8] A. Hirata, T. Fujita, Y.R. Wen, J.H. Schneibel, C.T. Liu, and M.W. Chen, Nat Mater, 10 (2011) pp. 922-926.

[9] C.A. Williams, P. Unifantowicz, N. Baluc, G.D.W. Smith, and E.A. Marquis, Acta Mater, 61 (2013) pp. 2219-2235.

[10] C.A. Williams, G.D.W. Smith, and E.A. Marquis, Scripta Mater, 67 (2012) 108111.

[11] P. He, M. Klimenkov, R. Lindau, and A. Moslang, J Nucl Mater, 428 (2012) pp. 131-138.

[12] T. Liu, H. Shen, C. Wang, and W. Chou, Mater Res Innov, 18 (2014) pp. 410-413.

[13] Z.H. Yao, W.H. Xiong, G.P. Zhang, X. Chen, and B. Huang, Mater Design, 56 (2014) pp. 953-958.

[14] Y. Ortega, V. de Castro, M.A. Monge, A. Munoz, T. Leguey, and R. Pareja, J Nucl Mater, 376 (2008) pp. 222-228.

[15] J. Xu, C.T. Liu, M.K. Miller, and H.M. Chen, Phys Rev B, 79 (2009).

[16] Y. Ortega, M.A. Monge, V. de Castro, A. Munoz, T. Leguey, and R. Pareja, J Nucl Mater, 386-88 (2009) pp. 462-465.

[17] R. Pareja, P. Parente, A. Munoz, A. Radulescu, and V. de Castro, Philos Mag, 95 (2015) pp. 2450-2465.

[18] R.W. Siegel, Annu Rev Mater Sci, 10 (1980) pp. 393-425.

[19] M.J. Puska, and R.M. Nieminen, Rev Mod Phys, 66 (1994) pp. 841-897.

[20] P. AsokaKumar, M. Alatalo, V.J. Ghosh, A.C. Kruseman, B. Nielsen, and K.G. Lynn, Phys Rev Lett, 77 (1996) pp. 2097-2100.

[21] M.A. Auger, T. Leguey, A. Munoz, M.A. Monge, V. de Castro, P. Fernandez, G. Garces, and R. Pareja, J Nucl Mater, 417 (2011) pp. 213-216.

[22] M.A. Auger, V. de Castro, T. Leguey, M.A. Monge, A. Munoz, and R. Pareja, J Nucl Mater, 442 (2013) S142-S147. 
[23] M.A. Auger, V. de Castro, T. Leguey, J. Tarcisio-Costa, M.A. Monge, A. Munoz, and R. Pareja, J Nucl Mater, 455 (2014) pp. 600-604.

[24] P. Kirkegaard, N.J. Pedersen, and M. Eldrup, Risø Report M2740, Risø National Laboratory, Denmark, (1989).

[25] A. Vehanen, P. Hautojarvi, J. Johansson, J. Ylikauppila, and P. Moser, Phys Rev B, 25 (1982) pp. 762-780.

[26] V. Krsjak, Z. Szaraz, and P. Hahner, J Nucl Mater, 428 (2012) pp. 160-164.

[27] M.J. Puska, and R.M. Nieminen, J Phys F Met Phys, 13 (1983) pp. 333-346.

[28] H. Ohkubo, Z. Tang, Y. Nagai, M. Hasegawa, T. Tawara, and M. Kiritani, Mat Sci Eng A-Struct, 350 (2003) pp. 95-101.

[29] J. Kuriplach, O. Melikhova, C. Domain, C.S. Becquart, D. Kulikov, L. Malerba, M. Hou, A. Almazouzi, C.A. Duque, and A.L. Morales, Appl Surf Sci, 252 (2006) pp. 3303-3308.

[30] M.A. Auger, T. Leguey, V. de Castro, M.A. Monge, and R. Pareja, Mater Sci Tech-Lond, 30 (2014) pp. 1704-1708.

[31] X. Wu, K.R. Hebert, P. Asoka-Kumar, and K.G. Lynn, J. Electrochem. Soc., 141 (1994) pp. 3361-3368.

[32] A. Hirata, T. Fujita, C.T. Liu, and M.W. Chen, Acta Mater, 60 (2012) pp. 56865696. 
Table 1: Isothermal annealing effect on the positron lifetime spectrum of as-forged Fe14CrY.

\begin{tabular}{|c|c|c|c|c|c|}
\hline Fe14CrY & $\begin{array}{c}\text { Annealing } \\
\text { time } \\
\text { (min) } \\
\end{array}$ & $\begin{array}{c}\tau_{1} \\
(\mathrm{ps})\end{array}$ & $\begin{array}{c}\tau_{2} \\
(\mathrm{ps})\end{array}$ & $\begin{array}{c}\mathrm{I}_{2} \\
(\%)\end{array}$ & $\begin{array}{c}\langle\tau\rangle \\
(\mathrm{ps})\end{array}$ \\
\hline As-forged & --- & $180 \pm 7$ & $256 \pm 16$ & $29 \pm 12$ & $202 \pm 60$ \\
\hline \multirow{3}{*}{+ Annealed at $800^{\circ} \mathrm{C}$} & 30 & $189 \pm 8$ & $265 \pm 50$ & $13 \pm 17$ & $199 \pm 80$ \\
\hline & 90 & $188 \pm 7$ & $273 \pm 40$ & $13 \pm 12$ & $199 \pm 60$ \\
\hline & 270 & $188 \pm 6$ & $278 \pm 40$ & $13 \pm 11$ & $200 \pm 60$ \\
\hline \multirow{3}{*}{+ Annealed at $850^{\circ} \mathrm{C}$} & 30 & $154 \pm 50$ & $217 \pm 22$ & $70 \pm 50$ & $204 \pm 200$ \\
\hline & 90 & $120 \pm 30$ & $209 \pm 3$ & $89 \pm 7$ & $199 \pm 20$ \\
\hline & 270 & $119 \pm 13$ & $217 \pm 3$ & $80 \pm 4$ & $197 \pm 18$ \\
\hline
\end{tabular}


Figure 1. Isochronal annealing effect on the positron lifetime parameters for the ODS $\mathrm{Fe} 14 \mathrm{Cr}$ alloy (Fe14CrY) in different conditions: a) as-HIP, b) as-forged and c) heat treated after forging.

Figure 2. Isochronal annealing effect on the positron lifetime parameters for the alloys: a) Fe14CrYWTi heat treated at $850{ }^{\circ} \mathrm{C}$ after forging, b) Fe14CrWTiY heat treated at $1300{ }^{\circ} \mathrm{C}$ and c) non-ODS Fe $14 \mathrm{Cr}$ heat treated at $850{ }^{\circ} \mathrm{C}$ after forging.

Figure 3. CDB ratio spectra for the ODS Fe14CrY alloy isochronally annealed at

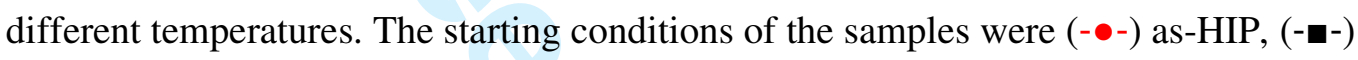
as-forged and (- $\left.\boldsymbol{\Delta}^{-}\right)$heat treated at $850^{\circ} \mathrm{C}$ after forging. The $\mathrm{CDB}$ ratio curves for $\mathrm{Fe}$, $\mathrm{Cr}$ and $\mathrm{Y}_{2} \mathrm{O}_{3}$ are shown for comparison.

Figure 4. Isochronal annealing effect on the CDB ratio spectra for (-๑-) Fe14CrYWTi heat treated at $850{ }^{\circ} \mathrm{C}$ after forging, and (-m-) Fe14CrWTiY heat treated at $1300{ }^{\circ} \mathrm{C}$. The $\mathrm{CDB}$ ratio curves for $\mathrm{Fe}, \mathrm{Cr}, \mathrm{W}, \mathrm{Ti}, \mathrm{Si}$ and $\mathrm{Y}_{2} \mathrm{O}_{3}$ oxide are shown for comparison.

Figure 5. S-W plots obtained from CDB data for the ODS and non-ODS Fe14Cr alloys isochronally annealed. 
Isochronal annealing effect on the positron lifetime parameters for the ODS Fe14Cr alloy ( $\mathrm{Fe} 14 \mathrm{CrY})$ in different conditions: a) as-HIP, b) as-forged and c) heat treated after forging. $239 \times 182 \mathrm{~mm}(300 \times 300 \mathrm{DPI})$ 

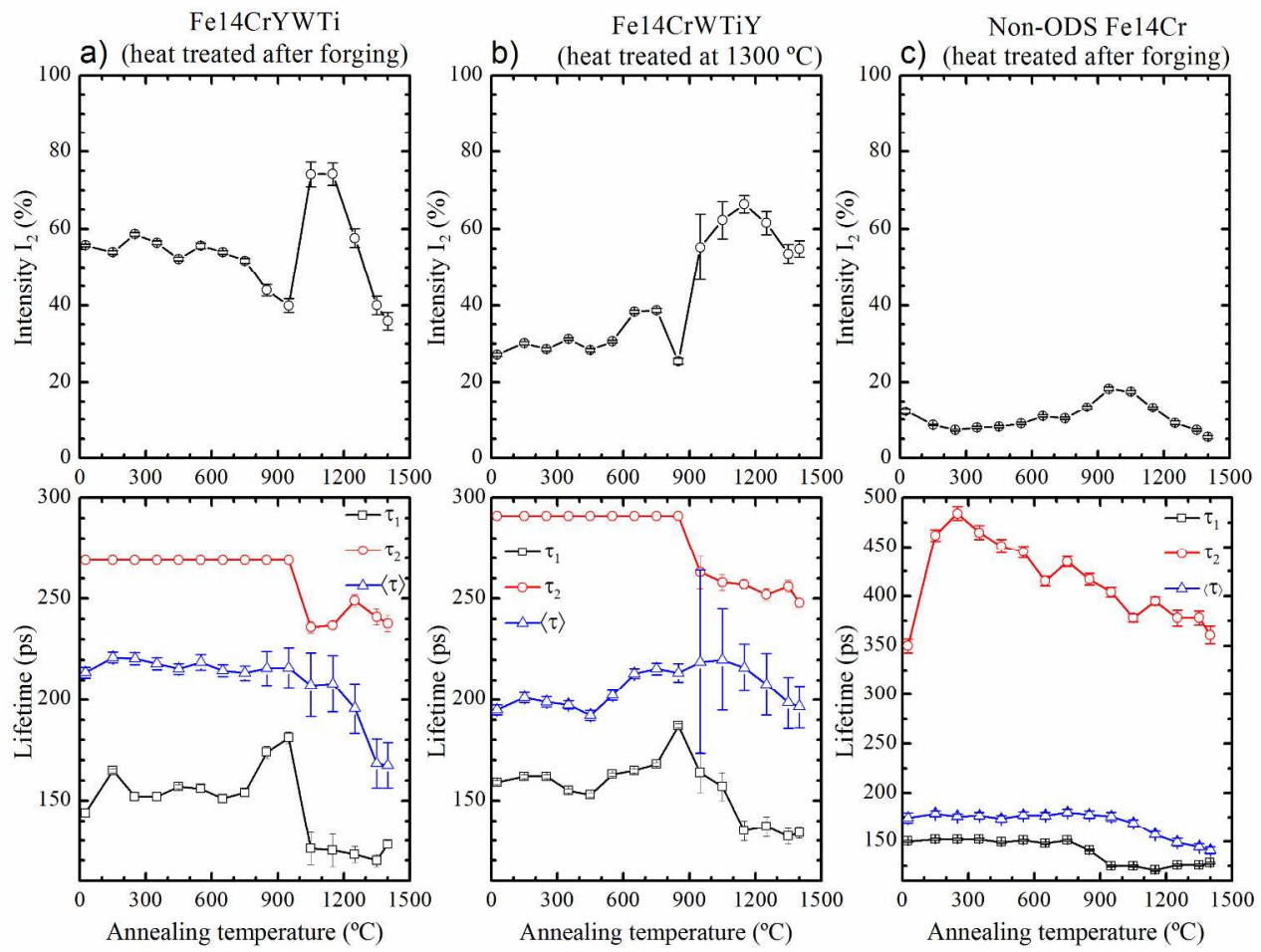

Isochronal annealing effect on the positron lifetime parameters for the alloys: a) Fe14CrYWTi heat treated at $850^{\circ} \mathrm{C}$ after forging, b) Fe14CrWTiY heat treated at $1300{ }^{\circ} \mathrm{C}$ and $\mathrm{c}$ ) non-ODS Fe14Cr heat treated at $850{ }^{\circ} \mathrm{C}$ after forging.

$238 \times 178 \mathrm{~mm}(300 \times 300 \mathrm{DPI})$ 

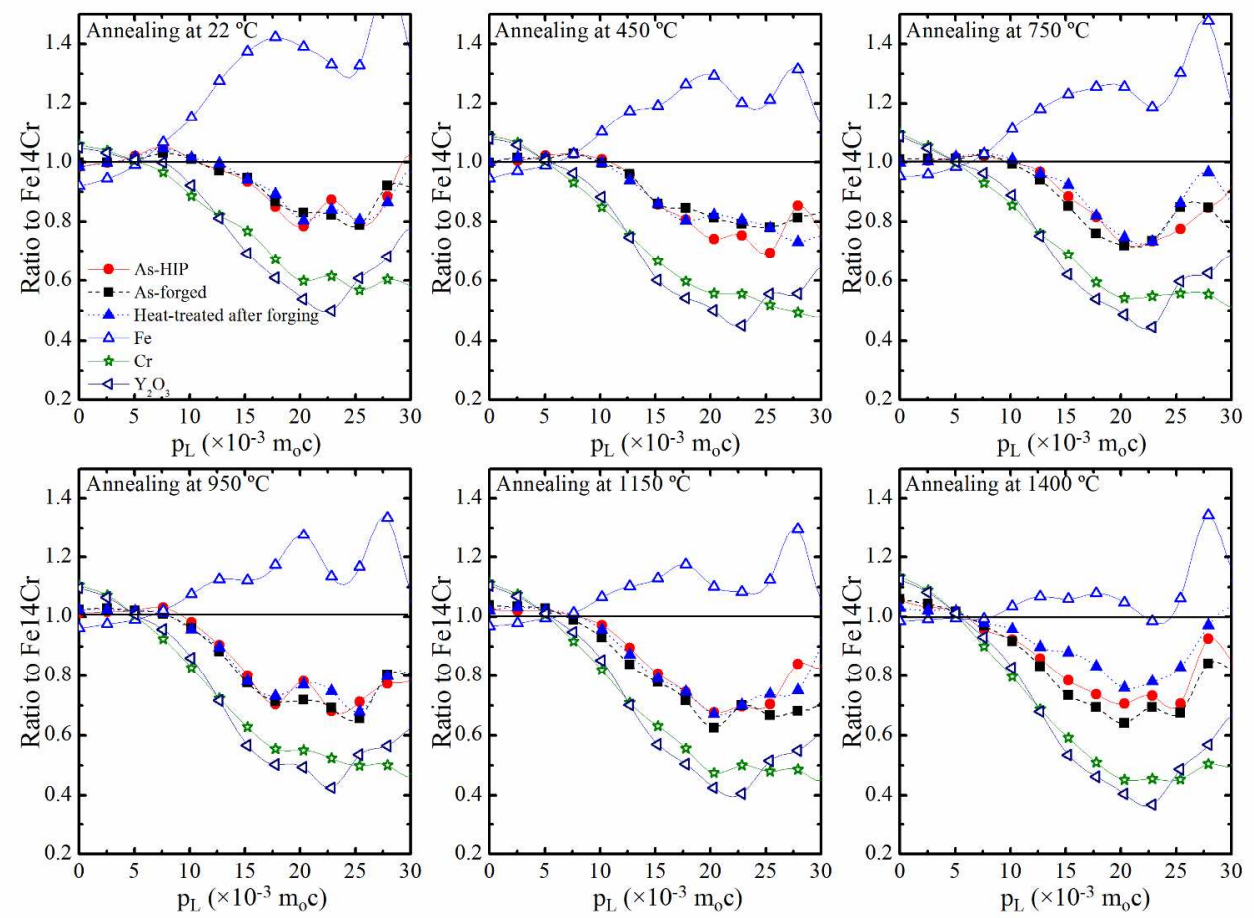

CDB ratio spectra for the ODS Fe14CrY alloy isochronally annealed at different temperatures. The starting

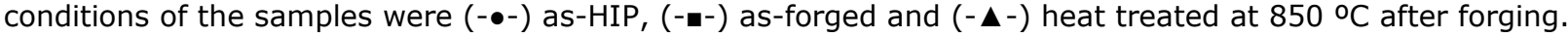
The CDB ratio curves for $\mathrm{Fe}, \mathrm{Cr}$ and $\mathrm{Y} 2 \mathrm{O} 3$ are shown for comparison. $238 \times 176 \mathrm{~mm}(300 \times 300$ DPI) 
Isochronal annealing effect on the CDB ratio spectra for (-•-) Fe14CrYWTi heat treated at $8500^{\circ} \mathrm{C}$ after forging, and (-m-) Fe14CrWTiY heat treated at $1300^{\circ} \mathrm{C}$. The CDB ratio curves for $\mathrm{Fe}, \mathrm{Cr}, \mathrm{W}, \mathrm{Ti}, \mathrm{Si}$ and Y2O3 oxide are shown for comparison.

$238 \times 175 \mathrm{~mm}(300 \times 300 \mathrm{DPI})$ 

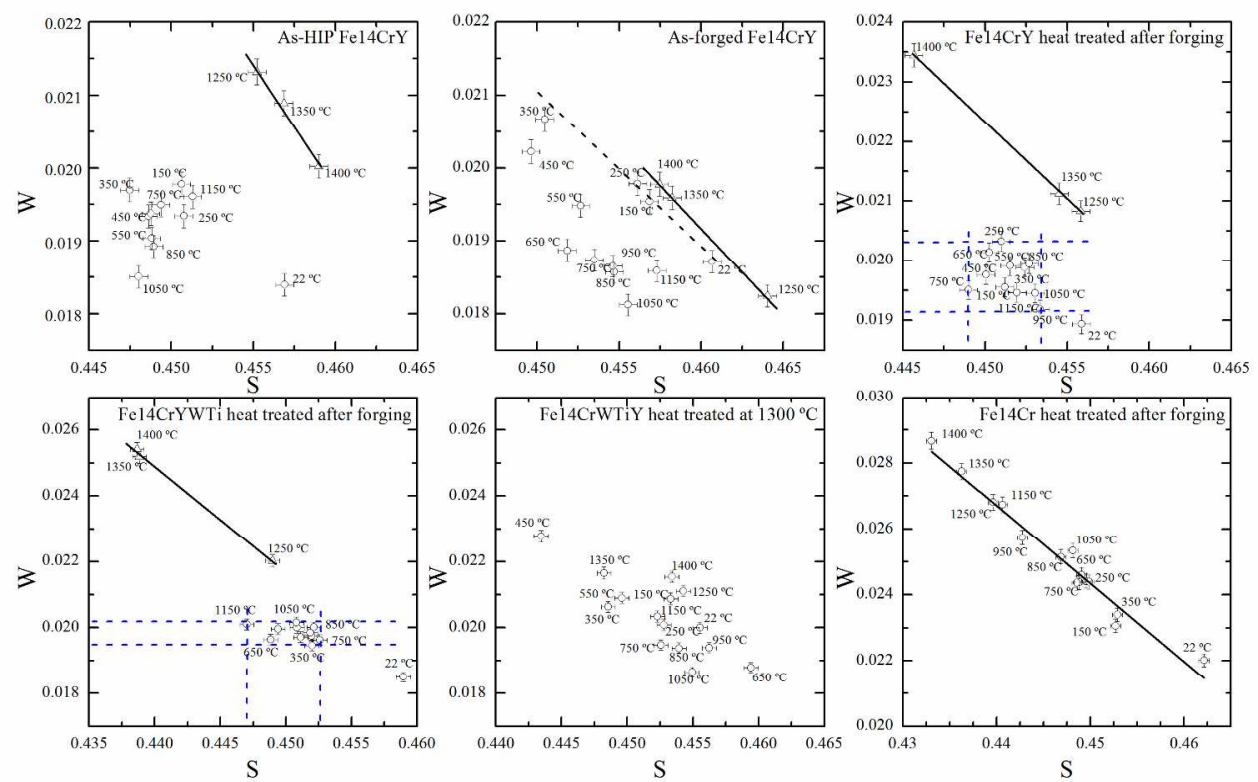

S-W plots obtained from CDB data for the ODS and non-ODS Fe14Cr alloys isochronally annealed. $240 \times 152 \mathrm{~mm}(300 \times 300 \mathrm{DPI})$ 
Table 1: Isothermal annealing effect on the positron lifetime spectrum of as-forged Fe14CrY.

\begin{tabular}{|l|c|c|c|c|c|}
\hline \multicolumn{1}{|c|}{ Fe14CrY } & $\begin{array}{c}\text { Annealing } \\
\text { time } \\
(\mathrm{min})\end{array}$ & $\begin{array}{c}\tau_{1} \\
(\mathrm{ps})\end{array}$ & $\begin{array}{c}\tau_{2} \\
(\mathrm{ps})\end{array}$ & $\begin{array}{c}\mathrm{I}_{2} \\
(\%)\end{array}$ & $\begin{array}{c}\langle\tau\rangle \\
(\mathrm{ps})\end{array}$ \\
\hline \hline & & & & & \\
\hline & --- & $180 \pm 7$ & $256 \pm 16$ & $29 \pm 12$ & $202 \pm 60$ \\
\hline As-forged & 30 & $189 \pm 8$ & $265 \pm 50$ & $13 \pm 17$ & $199 \pm 80$ \\
\hdashline & 90 & $188 \pm 7$ & $273 \pm 40$ & $13 \pm 12$ & $199 \pm 60$ \\
\hline & 270 & $188 \pm 6$ & $278 \pm 40$ & $13 \pm 11$ & $200 \pm 60$ \\
\hline Annealed at $850^{\circ} \mathrm{C}$ & 90 & $120 \pm 30$ & $209 \pm 3$ & $89 \pm 7$ & $199 \pm 20$ \\
& 30 & $154 \pm 50$ & $217 \pm 22$ & $70 \pm 50$ & $204 \pm 200$ \\
& 270 & $119 \pm 13$ & $217 \pm 3$ & $80 \pm 4$ & $197 \pm 18$ \\
\hline
\end{tabular}




\section{Positron annihilation study of the vacancy clusters in ODS Fe-14Cr alloys}
R. Domínguez-Reyes ${ }^{\mathrm{a}^{*}}$, M. A. Auger ${ }^{\mathrm{a}, \mathrm{b}}$, M. A. Monge ${ }^{\mathrm{a}}$ and R. Pareja ${ }^{\mathrm{a}}$
${ }^{a}$ Departamento de Física, Universidad Carlos III de Madrid, Avda. de la Universidad 30. 28911 Leganés, Madrid, Spain.

${ }^{b}$ Department of Materials, University of Oxford. OX1 3PH Oxford, UK.

* Corresponding author. E-mail address: rdomingu@ fis.uc3m.es (R. Domínguez-Reyes) 


\section{Positron annihilation study of the vacancy clusters in ODS Fe-14Cr alloys}

Oxide dispersion strengthened $\mathrm{Fe} 14 \mathrm{Cr}$ and $\mathrm{Fe} 14 \mathrm{CrWTi}$ alloys produced by mechanical alloying and hot isostatic pressing were subjected to isochronal annealing up to $1400{ }^{\circ} \mathrm{C}$, and the evolution and thermal stability of the vacancy type defects were investigated by positron annihilation spectroscopy. The results were compared to those from a non-oxide dispersion strengthened $\mathrm{Fe} 14 \mathrm{Cr}$ alloy produced by following the same powder metallurgy route. The long lifetime component of the positron annihilation spectra revealed the existence of tridimensional vacancy clusters, or nanovoids, in all these alloys. Two recovery stages are found in the oxide dispersion strengthened alloys irrespective of the starting conditions of the samples. The first one starting at $\mathrm{T}>750{ }^{\circ} \mathrm{C}$ is attributed to thermal shrinkage of large vacancy clusters, or voids. A strong increase in the intensity of the long lifetime after annealing at temperatures in the $800-1050{ }^{\circ} \mathrm{C}$ range indicates the development of new vacancy clusters. These defects appear to be unstable above $1050{ }^{\circ} \mathrm{C}$, but some of them remain at temperatures as high as $1400{ }^{\circ} \mathrm{C}$, at least for $90 \mathrm{~min}$.

Keywords: word; positron annihilation, steel, ODS alloys, vacancy clusters

\section{Introduction}

Dispersion strengthened ferritic Fe-Cr alloys with $\mathrm{Y}_{2} \mathrm{O}_{3}$ addition are presently considered one of the most promising structural materials for the future fusion reactors and generation IV fission reactors due to their enhanced high temperature strength, microstructural stability, radiation resistance, and good creep resistance at high temperature [1-4]. The appropriate powder metallurgy processing of these alloys develops a homogeneous dispersion of nano-sized hard particles that governs these mandatory properties. Analytical transmission electron microscopy (TEM) and atom probe tomography (APT) studies have contributed to reveal the dimensional, structural and compositional characteristics of the nanoparticles present in these alloys [5-9]. The 
fundamental elements of these nano-features are $\mathrm{O}, \mathrm{Y}$ and $\mathrm{Cr}$, and some alloying impurities intentionally or accidentally added such as $\mathrm{Ti}, \mathrm{Al}$ or $\mathrm{Si}$ [10-13], which appear to refine the size and increase the number density and stability of these nano-features. Experimental evidences for defective nanoclusters, or nano-features, in the ODS steel with a nominal composition Fe-14Cr-3.0W-0.4Ti-0.24Y2O3 (wt\%), denoted as 14YWTi, have been found from analytical and high resolution transmission electron microscopy (TEM) studies [8]. There are also positron annihilation spectroscopy (PAS) results that point out certain association between vacancy clusters, or nanovoids, and the oxide dispersion in ODS steels [14-16]. It should be noticed that there are PAS results showing vacancy clustering, as well the opposite, in non-ODS steels processed following a powder metallurgy (PM) route similar to the ODS ones, i.e. mechanical alloying (MA) and hot isostatic pressing (HIP) consolidation [14, 17]. It is the case of the non-ODS steels with nominal composition $\mathrm{Fe}-12 \mathrm{wt} \% \mathrm{Cr}$ showing no evidence of tridimensional vacancy clusters in the as-HIP condition, but these clusters were detected after a heat treatment at $850^{\circ} \mathrm{C}$ [17]. These results suggest that the designedly addition of solutes such as $\mathrm{Y}$ and Ti would not be the decisive factors for vacancy clustering associated to the oxide nano-features in the ODS steels but the processing conditions and the thermal history of the alloy.

To evidence the above and provide a better understanding on the role of the vacancies in the formation of nano-features in the ODS steels, and on the vacancy cluster behavior, a series of comprehensive isochronal annealing experiments and PAS measurements have been accomplished in ODS Fe14Cr alloys, with and without (W+Ti) addition, and in the counterpart non-ODS Fe14Cr alloy. PAS is a successful technique to study vacancy-type defects in metals and alloys [18]. Lattice defects such as vacancies, voids, solute-vacancy complexes and other open-volume defects are 
effective traps for thermalized positrons in a solid. When a positron annihilates trapped in a defect, the annihilation radiation conveys information about the defect. The positron lifetime distribution provides information on the type, size and concentration of the defects. In addition, the Doppler broadening of the annihilation radiation peak at 511 $\mathrm{keV}$, which depends on the momentum of the electrons annihilating with the thermalized positrons, can give information about the chemical surround of the positron annihilation sites $[19,20]$. Thus, the concurrent positron lifetime spectroscopy (PLS) and coincidence Doppler broadening (CDB) measurements in isochronally annealed samples would contribute to assess the recovery kinetics of the vacancy defects and their stability in relation with the solute impurities in the ODS alloys. The understanding and assessment of these subjects are of prime interest for developing irradiation-resistant and high-temperature alloys for structural applications. The stability and recovery of radiation-induced defects would be associated with the inherent vacancy-type defects and nano-features present in the ODS alloys, as these can act as strong sinks for lattice defects induced by radiation. The results would contribute to predict the stability of the nano-featured ODS Fe-Cr alloys under the working conditions.

\section{Experimental}

ODS alloys with target compositions: Fe-14Cr-0.3 $\mathrm{Y}_{2} \mathrm{O}_{3}$ (wt \%), Fe-14Cr-2W-0.3Ti-0.3 $\mathrm{Y}_{2} \mathrm{O}_{3}(\mathrm{wt} \%)$ and $\mathrm{Fe}-14 \mathrm{Cr}-2 \mathrm{~W}-0.3 \mathrm{Ti}-0.24 \mathrm{Y}$ (wt \%), and a non-ODS Fe-14Cr alloy (wt $\%$ ), were processed by a PM route consisting of MA and consolidation by HIP for $2 \mathrm{~h}$ at $1100{ }^{\circ} \mathrm{C}$ and $200 \mathrm{MPa}$. These alloys are hereafter denoted as Fe14CrY, Fe14CrYWTi, Fe14CrWTiY and Fe14Cr, respectively. The processing details are found elsewhere [21-23]. The consolidated billets of Fe14CrY, Fe14CrYWTi and Fe14Cr ( 30 mm $\varnothing$ 
$\times 55 \mathrm{~mm}$ ) were forged between 1050 and $1150^{\circ} \mathrm{C}$ into the form of $\sim 12 \times 12 \times 170 \mathrm{~mm}$ bars, and afterwards heat treated for $2 \mathrm{~h}$ at $850^{\circ} \mathrm{C}$ and air cooled. The Fe14CrWTiY alloy was not forged but heat treated for $1 \mathrm{~h}$ at $1300^{\circ} \mathrm{C}$. Sample pairs with dimensions $10 \times 10 \times 1 \mathrm{~mm}$ were cut by electro-erosion from the ingots, and then their surfaces mechanically polished to a mirror finishing using alumina slurry. The PAS experiments were performed on sample pairs after successive isochronal annealing for $90 \mathrm{~min}$ from room temperature and up to $1400^{\circ} \mathrm{C}$ in $100{ }^{\circ} \mathrm{C}$ steps in a vacuum pressure $<10^{-5}$ mbar. The isochronal annealing experiments in the Fe14CrY alloy were performed on three pairs of samples with different starting conditions: as-HIP, as-forged, and heat treated at $850{ }^{\circ} \mathrm{C}$ after forging. The starting condition for the Fe14CrYWTi and $\mathrm{Fe} 14 \mathrm{Cr}$ alloys was the thermal treatment at $850^{\circ} \mathrm{C}$ after forging, and for the Fe14CrWTiY alloy the thermal treatment at $1300^{\circ} \mathrm{C}$.

The positron annihilation experiments were carried out in a fast-fast coincidence spectrometer with a time resolution of 230 ps (FWHM) using a ${ }^{22} \mathrm{Na}$ source sealed in kapton sandwiched between the pair of samples. Positron lifetime spectra with a total count number $>10^{6}$ were properly fitted to a sum of two lifetime components, $\tau_{1}$ and $\tau_{2}$, after subtracting the corrections due to positron annihilation in the ${ }^{22} \mathrm{Na}$ source. These spectra are characterized by a mean positron lifetime defined as

$$
\langle\tau\rangle=\tau_{1} I_{1}+\tau_{2} I_{2}
$$

where $I_{1}$ and $I_{2}$ are intensities of the corresponding components. The instrumental time resolution and contribution of the positron source to the lifetime spectra were determined from measurements on reference samples of annealed pure $\mathrm{Fe}$ and Si single crystals. The PATFIT-88 package was used for fitting the spectra [24]. 
Coincidence Doppler broadening measurements were done using two HP Ge detectors in timing coincidence, placed face to face with the samples at the half-way point between the detectors. The resulting CDB spectrum was the cumulative spectrum of $24 \mathrm{CDB}$ spectra without evidence of electronic shift, each of them with a count number $>10^{6}$ in a $512 \times 512$ coincidence matrix. The cumulative spectra had $1 \times 10^{7}$ counts in the strip centered on the matrix diagonal for the energy range $2 m_{0} c^{2}-1.6$ $\mathrm{keV}<E_{1}+E_{2}<2 m_{\mathrm{o}} c^{2}+1.6 \mathrm{keV} ; E_{1}$ and $E_{2}$ stand for the energies of the pair of annihilating photons, $m_{o}$ the electron rest mass and $c$ the light speed. The spectra were binned from 40 to 512 bins with a bin width of $2.5 \times 10^{-3} m_{o} c$ to decrease the statistical fluctuations of the data in the high momentum region. The spectra were then normalized and the intensity at a given photon momentum divided by the corresponding counts in the CDB spectrum of a reference sample in order to highlight the differences between the spectra. Pure annealed $\mathrm{Fe}$ and $\mathrm{Cr}$, and pure $\mathrm{Y}_{2} \mathrm{O}_{3}$ were used as reference samples. The fraction of positron annihilating with low- and high-momentum electrons was also measured using the $S$ and $W$ line shape parameters. The $S$ parameter was calculated as the ratio of the count number in the energy window of $1.946 \mathrm{keV}$ centered at $511 \mathrm{keV}$ to the count total in the annihilation peak. The $\mathrm{W}$ parameter was calculated as the fraction of counts in the energy interval $515.66-519.72 \mathrm{keV}$ and $502.67-506.74 \mathrm{keV}$.

\section{Results}

\subsection{Positron lifetime measurements}

The evolution of $\tau_{1}, \tau_{2},\langle\tau\rangle$ and $I_{2}$ as a function of annealing temperature is represented in Figures 1 and 2. All the alloys exhibited a two-component spectrum through the annealing temperature range except $\mathrm{Fe} 14 \mathrm{CrY}$ in the as-HIP condition, which yielded a single-component after annealing at $950{ }^{\circ} \mathrm{C}<\mathrm{T}<1350{ }^{\circ} \mathrm{C}$, see Figure 1a). The lifetime 
value of the second component, $\tau_{2}$, for $\mathrm{Fe} 14 \mathrm{Cr}$ heat treated after forging decays monotonously from $\sim 480$ ps to $\sim 360$ ps through the temperature range, see Figure 2c). In contrast, the ODS alloys presented a visible recovery of the $\tau_{2}$ value with onset at temperatures between 750 and $950^{\circ} \mathrm{C}$, which seems to depend on the treatments underwent after their HIP consolidation as the plots represented in Figures 1 and 2 reveal. Up to the recovery temperature, the $\tau_{2}$ value remained essentially constant for these alloys except for $\mathrm{Fe} 14 \mathrm{CrY}$ in the as-forged condition. After annealing at $\mathrm{T}<950{ }^{\circ} \mathrm{C}$ the mean value of $\tau_{2}$ resulted in $(350 \pm 40)$ ps and $(293 \pm 24)$ ps for Fe14CrY in the starting conditions as-HIP and heat treated after forging, respectively, (269 \pm 9$)$ ps for Fe14CrYWTi heat treated after forging and (291 \pm 12$)$ ps for heat treated Fe14CrWTiY. In order to emphasize the changes accompanying the recovery, the dispersion in the $I_{2}$ values was limited constraining $\tau_{2}$ to the mean value above quoted for the corresponding spectra. Short lifetime values, ranging between 110 and 200 ps in these alloys, may be attributed to positron annihilation at an abundant variety of defects inherent to their complex microstructure such as single vacancies, divacancies or trivacancies, impurityvacancy complex, dislocations or defects associated with them as jogs, vacancies and impurity-vacancy complexes, defects at grain boundaries and interfaces, as well as defects related with second-phase precipitates [14, 25, 26]. Positron lifetime values between 220 and 400 ps appear to be characteristic of annihilation in tridimensional vacancy clusters or nanovoids in $\alpha-\mathrm{Fe}$ [27-29].

In the interpretation of the lifetime results the following remarks have to be considered. 1) The fact that positron lifetime spectra are inconsistent with a standard trapping model derives from the complex microstructure of these alloys as revealed by TEM analyses $[22,23,30]$. The high number density and variety of complex defects, heterogeneously distributed in many cases, prevent any precise and reliable information 
about the defects contributing to the short lifetime component even though a diffusionlimited trapping model is applied. 2) Attempts for decomposing the short lifetime component in those spectra that exhibited a $\tau_{1}$ value as high as $\sim 200 \mathrm{ps}$, increasing the total number count of the spectra or constraining the lifetime values, failed. These analyses resulted in unrealistic lifetime values, or alternatively, either negative or meaningless intensity values with very large errors, and unacceptable variances. The above remarks point out that the second lifetime component that appears in the ODS alloys after annealing at $950{ }^{\circ} \mathrm{C}$ would be essentially attributable to real changes in the positron traps induced by annealing. Moreover, specific information about the positron traps responsible for the short lifetime component cannot be achieved from the present results. Nevertheless, the partial recovery or transformation of these traps can be inferred from the changes in the lifetime $\tau_{1}$ and intensity $I_{1}=1-I_{2}$.

\section{1a. $\mathrm{Fe} 14 \mathrm{CrY}$}

Figure 1 summarizes the effect of the thermo-mechanical treatment on the annihilation parameters for the ODS Fe14CrY alloy. The second lifetime of $350 \mathrm{ps}$, present in the as-HIP condition, disappears completely after annealing at temperatures in the interval $950{ }^{\circ} \mathrm{C}<\mathrm{T}<1350{ }^{\circ} \mathrm{C}$ but a very strong second lifetime component of $\sim 250$ ps develops after annealing at $1350{ }^{\circ} \mathrm{C}$. This is observed along with a considerable reduction of the $\tau_{1}$ value, which indicates thermal activated vacancy release from defects contributing to the short lifetime component and formation of new open-volume defects. The evolution of $I_{2}$ indicates the recovery onset of vacancy-type defects at $750{ }^{\circ} \mathrm{C}$, which means that the defects responsible for the 350 ps component become unstable and start to release vacancies. These migrating vacancies appear to flow to strong vacancy sinks contributing to the short lifetime component, as its lifetime value rises from (195 \pm 2$)$ ps 
to $(220 \pm 1)$ ps up to developing tridimensional vacancy clusters that give rise to the observed second lifetime component of $\sim 250$ ps.

The alloy in the as-forged condition exhibits an initial second lifetime component of 260 ps with a much higher intensity $I_{2}$ than the one for the alloy in the asHIP condition, $28 \%$ against $1.2 \%$, see the corresponding plots in Figure 1. After annealing at $150{ }^{\circ} \mathrm{C}, I_{2}$ goes down to $9 \%$ and $\tau_{2}$ increases to $\sim 400 \mathrm{ps}$. These values remain practically constant after the successive anneals up to $750^{\circ} \mathrm{C}$. This indicates that a significant part of the defects responsible for this 260 ps component being smaller in size and very much abundant than those of $350 \mathrm{ps}$ in the as-HIP samples are unstable at $150{ }^{\circ} \mathrm{C}$. It should be noted that the forged material in the air-cooled condition may retain vacancies frozen as complex vacancy clusters. The vacancy release from these defects at $150{ }^{\circ} \mathrm{C}$ appears to promote coarsening of other more stable defects, although in competition with other vacancy sinks. The latter may be some of the defects that contribute to the short lifetime as the simultaneous increment in $\tau_{1}$ and $I_{1}$ shows. At $\mathrm{T}>750{ }^{\circ} \mathrm{C}$ the $\tau_{2}$ and $\tau_{1}$ values start to recover simultaneously. This can be interpreted as dissolution of the large voids responsible for the $\sim 380$ ps component and trapping of the released vacancies in some of the defects contributing to short positron lifetime, which turn into tridimensional vacancy clusters, or nanovoids. These clusters with lifetime values of (242 \pm 7$)$ ps survive after annealing at $1400^{\circ} \mathrm{C}$, for 90 minutes at least. This interpretation would be compatible with the fact that the $\langle\tau\rangle$ value is unaltered after the recovery of the 380 ps traps, see Figure 1b). As an alternative interpretation one can conceive that defects responsible for the lifetime of $\sim 240$ developed after annealing at $\mathrm{T}>750^{\circ} \mathrm{C}$ were actually present before but contributing to the short lifetime component. Then, it would be resolved by the fits after annealing out the 380 ps defects. However, if 
the number density of the 240 ps defects is unchanged after annealing at $\mathrm{T}>750{ }^{\circ} \mathrm{C}$ the $\langle\tau\rangle$ value should very likely decrease instead of remaining essentially constant.

The unexpected large uncertainty in the $I_{2}$ value for the as-forged samples after the isochronal anneal at $850{ }^{\circ} \mathrm{C}$, confirmed repeating the measurements at least 3 times, demanded attention, see Figure 1b). Thus, isothermal annealing experiments at $800{ }^{\circ} \mathrm{C}$ and $850^{\circ} \mathrm{C}$ were performed on a pair of samples starting from the as-forged and aircooled condition. The results are summarized in Table 1. After isothermal annealing for $30 \mathrm{~min}$ at $800{ }^{\circ} \mathrm{C}$ the second lifetime component yields $I_{2}$ and $\tau_{2}$ values of $(13 \pm 17) \%$ and $(265 \pm 50) \mathrm{ps}$, which remain essentially constant after isothermal annealing for 270 $\min$. The subsequent isothermal annealing at $850^{\circ} \mathrm{C}$ for 30 min induces a remarkable increase in the $I_{2}$ value and in its uncertainty, as well as a reduction in $\tau_{2}$. Afterwards, the $I_{2}$ and $\tau_{2}$ values appear to be constant after annealing beyond $90 \mathrm{~min}$. It is worth noticing that the $\tau_{1}$ value remains constant after isothermal annealing at $800{ }^{\circ} \mathrm{C}$ longer than $30 \mathrm{~min}$, but it lowers remarkably after isothermal annealing at $850{ }^{\circ} \mathrm{C}$ and becomes again constant when the annealing time is above $90 \mathrm{~min}$. This appears to reproduce the $\tau_{1}$ behavior at the recovery onset of $\tau_{2}$ in the as-forged Fe14CrY samples isochronally annealed, as the corresponding plot in Figure 1b) and results in Table 1 show. The evolution of $I_{2}$ for the Fe14CrY samples heat treated after forging exhibits an isochronal annealing behavior very similar to that for the samples in as-HIP condition, except for the vanishing of second lifetime component, as the comparison between the plots in Figure 1 reveals. After annealing at $1050{ }^{\circ} \mathrm{C}, I_{2}$ rises from 10 to 92 $\%$ accompanied by a drop in $\tau_{2}$ from $293 \pm 24$ to $218 \pm 3$ ps. At temperatures above 1050 ${ }^{\circ} \mathrm{C}, I_{2}$ decreases and $\tau_{2}$ increases, ending at values of $\sim 60 \%$ and $\sim 245 \mathrm{ps}$ after the final anneal at $1400{ }^{\circ} \mathrm{C}$, in concordance with the corresponding values for the other two pairs of Fe14CrY samples. In the samples heat treated after forging it is worth noticing the 
clear correlation of the onset of the $I_{2}$ recovery at $750{ }^{\circ} \mathrm{C}$ with the rise of $\tau_{1}$, as well as the simultaneous correspondence between the maximum values of $I_{2}$ with the minimum $\tau_{1}$ values, as the plots in Figure 1c) show. This correspondence is also evident in the other two pair of samples although it occurs at different temperatures.

Regarding the evolution of the mean positron lifetime $\langle\tau\rangle$ with isochronal annealing no significant changes are observed for the samples in the as-HIP or as-forged conditions. For the samples heat treated after forging, $\langle\tau\rangle$ appears to slightly rise after annealing at $950{ }^{\circ} \mathrm{C}$ remaining constant until $1350{ }^{\circ} \mathrm{C}$, and then decreases just below the initial value.

\section{1b. Fe14CrYWTi and Fe14CrWTiY}

As stated in Section 2, the starting conditions for the samples of these two alloys were different: thermal treatment at $850{ }^{\circ} \mathrm{C}$ after forging for $\mathrm{Fe} 14 \mathrm{CrYWTi}$ and heat treatment at $1300{ }^{\circ} \mathrm{C}$ for Fe14CrWTiY. Nevertheless, either alloys exhibit decrease of the $I_{2}$ above $750{ }^{\circ} \mathrm{C}$ accompanied by a rise of $\tau_{1}$ in the same way as the $\mathrm{Fe} 14 \mathrm{CrY}$ alloy, see the plots in Figure 2. Afterwards, $\tau_{1}$ and $\tau_{2}$ recover in coincidence with a steeply increase in $I_{2}$ up to attaining a maximum value after annealing at $\sim 1150^{\circ} \mathrm{C}$. Beyond this temperature, $\tau_{1}$ and $\tau_{2}$ are practically constant and the mean lifetime $\langle\tau\rangle$ drops due to the decrease of the intensity $I_{2}$, which implies annealing out of the open volume defects responsible for the second lifetime component being more evident for Fe14CrYWTi.

\section{1c. $\mathrm{Fe} 14 \mathrm{Cr}$}

The recovery characteristics of this non-ODS alloy, heat treated at $850{ }^{\circ} \mathrm{C}$ after forging, differ noticeably from those observed for the ODS alloys. The lifetime $\tau_{2}$ does not exhibit the distinctive steep recovery of the ODS alloys at $800-1000{ }^{\circ} \mathrm{C}$ but a 


\subsection{CDB measurements}

The characteristics of the ratio CDB curves and their evolution with isochronal annealing are shown for selected annealing temperatures in Figures 3 and 4, along with the ratio curves for the reference samples of the alloying elements and $\mathrm{Y}_{2} \mathrm{O}_{3}$. All the $\mathrm{CDB}$ curves at a given annealing temperature are normalized to the one for $\mathrm{Fe} 14 \mathrm{Cr}$ annealed at the corresponding temperature. No significant changes respect to the Fe14Cr samples are found in the low-momentum region, i.e. for $p_{L}<10 \times 10^{-3} m_{o} c$, after annealing at temperatures $\mathrm{T}<950^{\circ} \mathrm{C}$. In this region some changes are evident after annealing at $\mathrm{T} \geq 950^{\circ} \mathrm{C}$, except for the Fe14CrYWTi samples. By contrast, the annealing effect on the high-momentum side of the ratio curves of the ODS alloys is obvious. The remarkable reduction of the positron annihilations with high-momentum electrons, relative to the $\mathrm{Fe} 14 \mathrm{Cr}$ alloy, appears to be related to a major contribution of the core electrons of $\mathrm{Cr}$, or other alloying elements such as $\mathrm{Y}, \mathrm{W}$, Ti and $\mathrm{Si}$, in the annihilation 
events. Nevertheless, the effective changes over the high-momentum side appear not to follow a defined pattern revealing the characteristic signature of a particular alloying element. This result can be interpreted as evidence for competitive positron trapping in defects with a configurational surrounding that can either concurrently or separately contain $\mathrm{Cr}, \mathrm{Y}$ and other alloying impurities.

Figure 5 shows the $W-S$ correlation plots for all the samples. These plots are useful for revealing the presence of different positron traps or changes in the chemical surrounding of the positron annihilation sites during isochronal annealing. It is known in the case of positron annihilation taking place in two positron states, i.e. in a free state and in a trapped state in a single type of defect, or otherwise in two trapped state in two different types of defect, the measured line shape parameters $S$ and $W$ are given by [31]

$$
\begin{aligned}
& S=f_{1} S_{1}+\left(1-f_{1}\right) S_{2} \\
& W=f_{1} W_{1}+\left(1-f_{1}\right) W_{2}
\end{aligned}
$$

where $S_{\mathrm{i}}$ stand for the line shape parameters representative of the annihilations with the low momentum valence electrons for each state, and $W_{\mathrm{i}}$ the corresponding with the high momentum electrons. From Equation 2 the following correlation is found

$$
W=-R S+\left(W_{2}+R S_{2}\right)
$$

where $\mathrm{R}$ is a constant defect specific parameter independent of the number density of positron traps given by

$$
R=\frac{W_{1}-W_{2}}{S_{2}-S_{1}}=\frac{W-W_{2}}{S_{2}-S}
$$

and the measured values of $S$ and $W$ are in the range $S_{1}<S<S_{2}$ and $W_{2}<W<W_{1}$. Then, if the $W-S$ plot exhibits a full linear dependence, either a single type of defect acts 
as positron traps or there exists positron trapping saturation in two effective defects through the recovery and isochronal annealing. This is the case for non-ODS Fe14Cr, see the corresponding plot in Figure 5. In contrast, the plots for the ODS alloys only exhibit a linear dependence after annealing at $\mathrm{T}>1150{ }^{\circ} \mathrm{C}$ except for $\mathrm{Fe} 14 \mathrm{CrWTiY}$ heat treated at $1300{ }^{\circ} \mathrm{C}$.

\section{Discussion}

\section{1. $\mathrm{Fe} 14 \mathrm{CrY}$ \\ 4.1a. As-forged samples}

Among the different samples investigated, it is expected that the ODS Fe14Cr samples in the as-forged condition achieve the most far out of equilibrium microstructure because of the fast cooling rate after forging at $1100{ }^{\circ} \mathrm{C}$. The large increase of $\tau_{2}$ simultaneously with the significant drop of $I_{2}$ after annealing at $150{ }^{\circ} \mathrm{C}$ reveals thermal shrinking of metastable vacancy clusters and coarsening of stable ones via trapping of migrating vacancies. These large tridimensional clusters or voids are thermally stable up to $750^{\circ} \mathrm{C}$. Above this temperature these voids become unstable, the representative positron lifetime $\tau_{2}$ for the voids drops steeply and the intensity $I_{2}$ rises simultaneously, see Figure 1b). This can only be interpreted as a sign of development of new vacancy clusters at the expenses of the vacancies released from unstable voids during their thermal shrinkage. The characteristic $\tau_{2}$ value for the new clusters results to be $235 \pm 10$ ps after annealing at $\mathrm{T} \geq 950^{\circ} \mathrm{C}$. The fact that the $W-S$ plot for these samples exhibits a constant $R$ value of $0.2330 \pm 0.0010$ for annealing temperatures $\mathrm{T}>1150{ }^{\circ} \mathrm{C}$ concurrent with the constant value of $\tau_{2}$ supports the above interpretation. These clusters, as well as those appearing in the temperature range $150-750^{\circ} \mathrm{C}$, must be associated with some 
solute impurities that stabilize them in the corresponding temperature range. According with the calculi of the positron lifetime for tridimensional vacancy clusters in pure $\alpha$-Fe, these clusters could contain a number of 3 to 5 vacancies if solute impurities are not found associated with them $[25,26]$, but they would be unstable at $150{ }^{\circ} \mathrm{C}$ [22]. Some impurities would therefore have to be associated with the stable vacancy clusters.

Hence, the binding of solute atoms to these clusters would be reflected on the highmomentum region of the $\mathrm{CDB}$ spectrum by the contribution of core electrons from the solute atoms. After any annealing step, the high-momentum region of the CDB curves for Fe14CrY in the as-forged condition seems to exhibit characteristics compatible with both the $\mathrm{Cr}$ and $\mathrm{Y}$ signature, see Figure 3. No conclusive evidence for the association of vacancy clusters with an exclusive atom, i.e. either $\mathrm{Cr}$ or $\mathrm{Y}$ atoms, can be attained from these curves. Thus, the changes in the high-momentum region induced by successive isochronal annealing can be interpreted as the result of the concurrent contribution of core electrons from $\mathrm{Cr}$ and $\mathrm{Y}$ atoms associated with the positron traps.

\section{1b. Heat-treated samples after forging}

The effect of the heat treatment at $850{ }^{\circ} \mathrm{C}$ after forging is to shift the edge of the abrupt changes in $I_{2}, \tau_{2}$ and $\tau_{1}$ from $750{ }^{\circ} \mathrm{C}$ to $950{ }^{\circ} \mathrm{C}$, see Fig 1c). Nevertheless, these changes are preceded by a recovery of $I_{2}$ and a rise of $\tau_{1}$ indicating that: 1) some unstable vacancy clusters still remain after the pre-treatment at $850{ }^{\circ} \mathrm{C}$ for $2 \mathrm{~h}$, and 2) there exists a flow of the vacancies released from the shrinking clusters to some defects that contributes to the first lifetime component, as occurs for the samples annealed in the asforged condition. These defects would have capability for trapping vacancies giving rise to a variety of positron traps apparently stable at $1050^{\circ} \mathrm{C}$. Above this temperature, $I_{2}$ decreases rapidly with a simultaneous increase of $\tau_{2}$, which suggests shrinkage of some 
clusters and coarsening of others. However, the last anneal at $1400{ }^{\circ} \mathrm{C}$ lowers considerably the $\tau_{2}, \tau_{1}$ and $\langle\tau\rangle$ values revealing unstability of the defects, see Figure 1c). In these samples the linear correlation between the parameters $W$ and $S$ is also apparent after annealing at $\mathrm{T}>1150{ }^{\circ} \mathrm{C}$ with a parameter $\mathrm{R}$ of $0.2590 \pm 0.0021$ as the corresponding plot in Figure 5 reveals. For annealing at $\mathrm{T} \leq 1150{ }^{\circ} \mathrm{C}$ the $\mathrm{W}$ and $\mathrm{S}$ values are found apparently randomly distributed in a bound region suggesting a complex annihilation scheme in the samples with positron annihilations in more than two states. In contrast, this concentration of the $W$ and $S$ values does not occur for the as-forged samples. This difference in the evolution of the parameters $W$ and $S$ can be attributed to the pre-treatment at $850{ }^{\circ} \mathrm{C}$.

The comparison of the ratio CDB spectra with those for the as-forged samples reveals that the fast recovery of $I_{2}$ after annealing at $\mathrm{T}>1150{ }^{\circ} \mathrm{C}$ is related to a considerable reduction of the $\mathrm{Cr}$ and $\mathrm{Y}$ contribution to high-momentum annihilations, see Figure 3. The above and the fact that the defects induced by annealing at $1050{ }^{\circ} \mathrm{C}$ are clearly unstable at higher temperatures in the heat treated samples, in parallel with the significant drop of $\langle\tau\rangle$ after annealing at $1400{ }^{\circ} \mathrm{C}$, would indicate a relationship between the thermal stability of the defects and the presence of $\mathrm{Y}$ and $\mathrm{Cr}$ atoms in their surroundings.

\section{1c. As-HIP samples}

These samples through isochronal annealing at $\mathrm{T} \leq 950{ }^{\circ} \mathrm{C}$ replicate the evolution of the positron lifetime parameters observed in the samples heat treated after forging, see Figure 1 . Now, $I_{2}$ for $\mathrm{T} \leq 950^{\circ} \mathrm{C}$ is considerably smaller, and $\tau_{2}$ and $\tau_{1}$ larger, than the corresponding values for the samples heat treated after forging. However, it is worth to notice that in any case the $\langle\tau\rangle$ values for the $\mathrm{Fe} 14 \mathrm{CrY}$ alloy coincide just at the starting 
of the isochronal annealing experiments irrespective of the previous thermo-mechanical treatment. This result reveals that the HIP consolidated ODS Fe14Cr alloy contains an effective concentration of positron traps high enough to attain trapping saturation despite the subsequent treatments herein applied.

At temperatures above $950{ }^{\circ} \mathrm{C}$, the vacancy clusters responsible for the lifetime component of $350 \mathrm{ps}$ anneal out, and a single lifetime component emerges gradually increasing its lifetime up to a value of $220 \pm 1$ ps upon annealing at $1250^{\circ} \mathrm{C}$. It is worth to be aware that the lifetime of the vacancy clusters growing after annealing at $1050{ }^{\circ} \mathrm{C}$ is $218 \pm 3$ ps in the samples heat-treated after forging and $221 \pm 3$ in the as-forged samples. Then, the single lifetime component of 220 ps appears to be due to positron annihilation saturation in the vacancy clusters grown by annealing, which coarsen at $\mathrm{T}>1250{ }^{\circ} \mathrm{C}$ while their concentration declines as the plot in Figure 1a) reflects. This interpretation is supported by the corresponding $W-S$ plots in Figure 5. Now, in opposition to that occurring for the other two Fe14CrY samples the lineal $W$ dependence on $S$ for $\mathrm{T}>1150^{\circ} \mathrm{C}$ is decreasing with annealing temperature resulting in a defect specific parameter $\mathrm{R}$ of $0.349 \pm 0.019$. Furthermore, the random evolution of the data points through isochronal annealing at $\mathrm{T} \leq 1150^{\circ} \mathrm{C}$ reflects a starting defect structure in these samples that differs from those in the other two pair samples thermomechanically treated.

\subsection{Fe14CrYWTi heat-treated samples after forging}

The evolution of the lifetime parameters with isochronal annealing for these samples exhibits significant coincidences with the ODS Fe14Cr samples submitted to the same thermo-mechanical treatment as the respective plots in Figures 1c) and 2a) reveal. These are: 1) the $I_{2}$ recovery onset above $750{ }^{\circ} \mathrm{C}$ and simultaneous increase of $\tau_{1}$, and 2) the 
development of new vacancy clusters at $\mathrm{T}>950^{\circ} \mathrm{C}$ revealed by the abrupt rise of $I_{2}$ concurrently with a considerable drop in $\tau_{1}$ and $\tau_{2}$. By contrast, there exist evident differences: 1) at $\mathrm{T}>1150^{\circ} \mathrm{C}$, a remarkable recovery of the mean positron lifetime $\langle\tau\rangle$ appears with its onset at $1150{ }^{\circ} \mathrm{C}$ while the $\tau_{1}$ and $\tau_{2}$ values remain practically constant; and 2) at $\mathrm{T}<1050{ }^{\circ} \mathrm{C}$, the second lifetime component due to vacancy clusters yield $I_{2}$ values at least $\sim 2.5$ times higher than those for the Fe14CrY samples, and $\tau_{2}$ values considerably smaller, i.e. 270 ps against 292 ps. These noteworthy differences respect to the counterpart Fe14CrY samples can only be attributed to the $\mathrm{W}$ and Ti addition. Nevertheless, a linear relationship between $W$ and $S$ like the one for the Fe14CrY samples is satisfied after annealing at $\mathrm{T}>1150^{\circ} \mathrm{C}$ with a parameter $\mathrm{R}=0.322 \pm 0.006$, see the plots in Figure 5. For annealing a $\mathrm{T} \leq 1150^{\circ} \mathrm{C}$ the parameters $W$ and $S$ are found bounded inside an interval of values even narrower than the one for the counterpart pair of Fe14CrY samples being also attributable to the effect of the heat treatment at $850{ }^{\circ} \mathrm{C}$ after forging. As the $I_{2}$ value scales with the number concentration of the vacancy-type defects responsible for this lifetime component, and $\tau_{2}$ does it with the size, the positron lifetime results indicate that either $\mathrm{W}$ or Ti promotes the formation and refinement of the vacancy clusters. Since TEM studies of ODS Fe14CrWTi have revealed the capability of $\mathrm{Ti}$ for improving the dispersion of oxide particle via its incorporation into the oxide particle [32], the aforementioned differences should accordingly be associated with the Ti effect on the dispersion.

\subsection{Fe14CrWTiY heat-treated at $1300^{\circ} \mathrm{C}$}

The changes in the lifetime parameters for these samples are qualitatively similar to those found in Fe14CrYWTi as the plots in Figure 2 show, even though the respective pre-treatments were very different. A small recovery stage of $\mathrm{I}_{2}$ at $\mathrm{T}>750{ }^{\circ} \mathrm{C}$ followed 
by a strong rise of $I_{2}$, and a second recovery at $\mathrm{T}>1150{ }^{\circ} \mathrm{C}$ appear, which are accompanied by qualitative changes in $\tau_{2}, \tau_{1}$ and $\langle\tau\rangle$ similar to those observed in the Fe14CrYWTi samples. The fact that the $I_{2}$ values after annealing at $\mathrm{T} \leq 750{ }^{\circ} \mathrm{C}$ are a factor of $\sim 1.5$ to 2 smaller than the ones for Fe14CrYWTi may be attributed to annealing induced by the pre-treatment at $1300{ }^{\circ} \mathrm{C}$ for $1 \mathrm{~h}$. But, it should be noted that after the final isochronal anneals at $1350{ }^{\circ} \mathrm{C}$ and $1400{ }^{\circ} \mathrm{C}$, which were longer in time than the pre-treatment for Fe14CrYWTi, $I_{2}$ and $\langle\tau\rangle$ for Fe14CrWTiY stay at values significantly higher than those for Fe14CrYWTi, i.e. $50 \%$ and 200 ps against $40 \%$ and 170 ps. This result is compatible with a possible presence of defects more stable than the ones present in Fe14CrYTiW. This possibility is supported by the TEM analyses accomplished in these samples that evidence a clear effect of the unintentional $\mathrm{Si}$ impurities on the oxide dispersion characteristics developed [21]. It was found that complex Y-Si oxide nanoparticles developed predominantly instead of Y-Ti oxide dispersoids. In that case, the high stability of vacancy clusters in these samples might be attributed to their association with the Y-Si oxide dispersoids or Si solutes.

The $W-S$ plot for Fe14CrWTiY exhibits a clear difference respect to those for the other ODS alloys, see Figure 5. The transition to a linear correlation between $W$ and $S$ after annealing at $\mathrm{T}>1150^{\circ} \mathrm{C}$ is no longer evident, being very likely attributable to the pre-treatment at $1300{ }^{\circ} \mathrm{C}$. As a result the $W$ and $S$ values appear not to be correlated with the annealing temperature over the whole temperature range. This means that the nano-features resulting in these samples is more complex than those for the other ODS alloys, which could be attributed to the effect of Si impurities present in these samples according with the above discussion. As occurs in the Fe14CrY alloy, the ratio CDB spectra shown in Figure 4 do not exhibit any clear sign attributable to any of the alloying impurities over the whole range of annealing temperature. The ratio CDB 


\section{Conclusions}

Positron annihilation measurements were performed on samples of the $\mathrm{ODS} \mathrm{Fe} 14 \mathrm{Cr}$ and Fe14CrWTi alloys submitted to sequential isochronal annealing. The main findings are summarized as follows:

(1) Irrespective of the starting conditions of the samples, the results revealed the presence of tridimensional vacancy clusters, or defect nano-features, some of which can survive annealing at $1400{ }^{\circ} \mathrm{C}$ for $90 \mathrm{~min}$, at least.

(2) The evolution of the positron annihilation characteristics shows two recovery stages for these vacancy type defects. The first one starting at $\mathrm{T}>750{ }^{\circ} \mathrm{C}$ is attributed to thermal shrinkage of large vacancy clusters, or voids, and consequent trapping of the released vacancies by other defects of different nature.

(3) Annealing in the temperature interval $800<\mathrm{T} \leq 1050{ }^{\circ} \mathrm{C}$ gives rise to new vacancy clusters, whose number concentration is considerably higher than the one for the vacancy clusters existing at $\mathrm{T} \leq 750^{\circ} \mathrm{C}$. The new vacancy clusters start to anneal out at $\mathrm{T}>1050{ }^{\circ} \mathrm{C}$ in the $\mathrm{Fe} 14 \mathrm{CrY}$ samples and at $\mathrm{T}>1150{ }^{\circ} \mathrm{C}$ in $\mathrm{Fe} 14 \mathrm{CrYWTi}$ 
and Fe14CrWTiY. In the case of the Fe14CrY samples isochronally annealed starting from the as-forged condition, the new clusters appear to exhibit the highest thermal stability.

(4) The number concentration of the vacancy clusters present in the Fe14CrYWTi samples after annealing at $\mathrm{T} \leq 750^{\circ} \mathrm{C}$ is considerable higher, and their size smaller, compared with the corresponding ones in the Fe14CrWTiY samples. However, the major part of vacancy defects developed upon annealing at $~ 950$ ${ }^{\circ} \mathrm{C}$ result to be remarkably more stable in Fe14CrWTiY than in Fe14CrYWTi.

(5) The W-S plots for the ODS Fe14Cr and Fe14CrYWTi alloys reveal a clear transition in the relationship between these parameters after annealing at temperatures above $1050^{\circ} \mathrm{C}$. This is compatible with a change in the structure of the nano-features present in these alloys. This transition is not present in nonODS Fe14Cr alloys or in the case of the ODS Fe14CrWTiY alloy pre-heated at $1300{ }^{\circ} \mathrm{C}$.

\section{Acknowledgments}

This investigation was supported by the Spanish Ministry of Economy and Competitiveness (project ENE2012-39787-C06-05), Comunidad de Madrid (Spain) through the MULTIMATCHALLENGE (S2013/MIT-2862) and TECHNOFUSION (II)-CM (S2013/MAE2745 ) programs, and European Commission through the European Fusion Development Agreement (contracts 09-240 and 10-425).

\section{References}

[1] S. Ukai, and M. Fujiwara, J Nucl Mater, 307 (2002) 749-757.

[2] L.K. Mansur, A.F. Rowcliffe, R.K. Nanstad, S.J. Zinkle, W.R. Corwin, and R.E. Stoller, J Nucl Mater, 329 (2004) pp. 166-172.

[3] K.L. Murty, and I. Charit, J Nucl Mater, 383 (2008) pp. 189-195. 
[4] G.R. Odette, M.J. Alinger, and B.D. Wirth, Annu Rev Mater Res, 38 (2008) pp. 471-503.

[5] D.J. Larson, P.J. Maziasz, I.S. Kim, and K. Miyahara, Scripta Mater, 44 (2001) pp. 359-364.

[6] V. de Castro, E.A. Marquis, S. Lozano-Perez, R. Pareja, and M.L. Jenkins, Acta Mater, 59 (2011) pp. 3927-3936.

[7] M.K. Miller, and C.M. Parish, Mater Sci Tech-Lond, 27 (2011) pp. 729-734.

[8] A. Hirata, T. Fujita, Y.R. Wen, J.H. Schneibel, C.T. Liu, and M.W. Chen, Nat Mater, 10 (2011) pp. 922-926.

[9] C.A. Williams, P. Unifantowicz, N. Baluc, G.D.W. Smith, and E.A. Marquis, Acta Mater, 61 (2013) pp. 2219-2235.

[10] C.A. Williams, G.D.W. Smith, and E.A. Marquis, Scripta Mater, 67 (2012) 108111.

[11] P. He, M. Klimenkov, R. Lindau, and A. Moslang, J Nucl Mater, 428 (2012) pp. 131-138.

[12] T. Liu, H. Shen, C. Wang, and W. Chou, Mater Res Innov, 18 (2014) pp. 410-413.

[13] Z.H. Yao, W.H. Xiong, G.P. Zhang, X. Chen, and B. Huang, Mater Design, 56 (2014) pp. 953-958.

[14] Y. Ortega, V. de Castro, M.A. Monge, A. Munoz, T. Leguey, and R. Pareja, J Nucl Mater, 376 (2008) pp. 222-228.

[15] J. Xu, C.T. Liu, M.K. Miller, and H.M. Chen, Phys Rev B, 79 (2009).

[16] Y. Ortega, M.A. Monge, V. de Castro, A. Munoz, T. Leguey, and R. Pareja, J Nucl Mater, 386-88 (2009) pp. 462-465.

[17] R. Pareja, P. Parente, A. Munoz, A. Radulescu, and V. de Castro, Philos Mag, 95 (2015) pp. 2450-2465.

[18] R.W. Siegel, Annu Rev Mater Sci, 10 (1980) pp. 393-425.

[19] M.J. Puska, and R.M. Nieminen, Rev Mod Phys, 66 (1994) pp. 841-897.

[20] P. AsokaKumar, M. Alatalo, V.J. Ghosh, A.C. Kruseman, B. Nielsen, and K.G. Lynn, Phys Rev Lett, 77 (1996) pp. 2097-2100.

[21] M.A. Auger, T. Leguey, A. Munoz, M.A. Monge, V. de Castro, P. Fernandez, G. Garces, and R. Pareja, J Nucl Mater, 417 (2011) pp. 213-216.

[22] M.A. Auger, V. de Castro, T. Leguey, M.A. Monge, A. Munoz, and R. Pareja, J Nucl Mater, 442 (2013) S142-S147. 
[23] M.A. Auger, V. de Castro, T. Leguey, J. Tarcisio-Costa, M.A. Monge, A. Munoz, and R. Pareja, J Nucl Mater, 455 (2014) pp. 600-604.

[24] P. Kirkegaard, N.J. Pedersen, and M. Eldrup, Ris $\varnothing$ Report M2740, Ris $\varnothing$ National Laboratory, Denmark, (1989).

[25] A. Vehanen, P. Hautojarvi, J. Johansson, J. Ylikauppila, and P. Moser, Phys Rev B, 25 (1982) pp. 762-780.

[26] V. Krsjak, Z. Szaraz, and P. Hahner, J Nucl Mater, 428 (2012) pp. 160-164.

[27] M.J. Puska, and R.M. Nieminen, J Phys F Met Phys, 13 (1983) pp. 333-346.

[28] H. Ohkubo, Z. Tang, Y. Nagai, M. Hasegawa, T. Tawara, and M. Kiritani, Mat Sci Eng A-Struct, 350 (2003) pp. 95-101.

[29] J. Kuriplach, O. Melikhova, C. Domain, C.S. Becquart, D. Kulikov, L. Malerba, M. Hou, A. Almazouzi, C.A. Duque, and A.L. Morales, Appl Surf Sci, 252 (2006) pp. 3303-3308.

[30] M.A. Auger, T. Leguey, V. de Castro, M.A. Monge, and R. Pareja, Mater Sci Tech-Lond, 30 (2014) pp. 1704-1708.

[31] X. Wu, K.R. Hebert, P. Asoka-Kumar, and K.G. Lynn, J. Electrochem. Soc., 141 (1994) pp. 3361-3368.

[32] A. Hirata, T. Fujita, C.T. Liu, and M.W. Chen, Acta Mater, 60 (2012) pp. 56865696. 
Table 1: Isothermal annealing effect on the positron lifetime spectrum of as-forged $\mathrm{Fe} 14 \mathrm{CrY}$.

\begin{tabular}{|l|c|c|c|c|c|}
\hline \multicolumn{1}{|c|}{ Fe14CrY } & $\begin{array}{c}\text { Annealing } \\
\text { time } \\
(\mathrm{min})\end{array}$ & $\begin{array}{c}\tau_{1} \\
(\mathrm{ps})\end{array}$ & $\begin{array}{c}\tau_{2} \\
(\mathrm{ps})\end{array}$ & $\begin{array}{c}\mathrm{I}_{2} \\
(\%)\end{array}$ & $\begin{array}{c}\langle\tau\rangle \\
(\mathrm{ps})\end{array}$ \\
\hline \hline As-forged & --- & $180 \pm 7$ & $256 \pm 16$ & $29 \pm 12$ & $202 \pm 60$ \\
\hline & 30 & $189 \pm 8$ & $265 \pm 50$ & $13 \pm 17$ & $199 \pm 80$ \\
\hline Annealed at $800^{\circ} \mathrm{C}$ & 90 & $188 \pm 7$ & $273 \pm 40$ & $13 \pm 12$ & $199 \pm 60$ \\
& 270 & $188 \pm 6$ & $278 \pm 40$ & $13 \pm 11$ & $200 \pm 60$ \\
\hline & 30 & $154 \pm 50$ & $217 \pm 22$ & $70 \pm 50$ & $204 \pm 200$ \\
\hline Annealed at $850^{\circ} \mathrm{C}$ & 90 & $120 \pm 30$ & $209 \pm 3$ & $89 \pm 7$ & $199 \pm 20$ \\
& 270 & $119 \pm 13$ & $217 \pm 3$ & $80 \pm 4$ & $197 \pm 18$ \\
\hline
\end{tabular}


Figure 1. Isochronal annealing effect on the positron lifetime parameters for the ODS Fe14Cr alloy (Fe14CrY) in different conditions: a) as-HIP, b) as-forged and c) heat treated after forging.

Figure 2. Isochronal annealing effect on the positron lifetime parameters for the alloys: a) Fe14CrYWTi heat treated at $850^{\circ} \mathrm{C}$ after forging, b) Fe14CrWTiY heat treated at $1300{ }^{\circ} \mathrm{C}$ and c) non-ODS Fe14Cr heat treated at $850{ }^{\circ} \mathrm{C}$ after forging.

Figure 3. CDB ratio spectra for the ODS Fe14CrY alloy isochronally annealed at

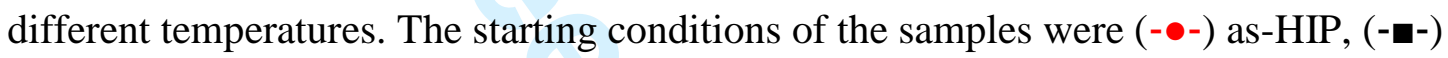
as-forged and (- $\left.\boldsymbol{\Delta}^{-}\right)$heat treated at $850^{\circ} \mathrm{C}$ after forging. The $\mathrm{CDB}$ ratio curves for $\mathrm{Fe}$, $\mathrm{Cr}$ and $\mathrm{Y}_{2} \mathrm{O}_{3}$ are shown for comparison.

Figure 4. Isochronal annealing effect on the CDB ratio spectra for (- $\bullet$-) Fe14CrYWTi heat treated at $850{ }^{\circ} \mathrm{C}$ after forging, and (-m-) Fe14CrWTiY heat treated at $1300{ }^{\circ} \mathrm{C}$. The $\mathrm{CDB}$ ratio curves for $\mathrm{Fe}, \mathrm{Cr}, \mathrm{W}, \mathrm{Ti}, \mathrm{Si}$ and $\mathrm{Y}_{2} \mathrm{O}_{3}$ oxide are shown for comparison.

Figure 5. S-W plots obtained from CDB data for the ODS and non-ODS Fe14Cr alloys isochronally annealed. 
Table 1: Isothermal annealing effect on the positron lifetime spectrum of as-forged Fe14CrY.

\begin{tabular}{|l|c|c|c|c|c|}
\hline Fe14CrY & $\begin{array}{c}\text { Annealing } \\
\text { time } \\
(\mathrm{min})\end{array}$ & $\begin{array}{c}\tau_{1} \\
(\mathrm{ps})\end{array}$ & $\begin{array}{c}\tau_{2} \\
(\mathrm{ps})\end{array}$ & $\begin{array}{c}\mathrm{I}_{2} \\
(\%)\end{array}$ & $\begin{array}{c}\langle\tau\rangle \\
(\mathrm{ps})\end{array}$ \\
\hline \hline As-forged & --- & $180 \pm 7$ & $256 \pm 16$ & $29 \pm 12$ & $202 \pm 60$ \\
\hline + Annealed at $800^{\circ} \mathrm{C}$ & 90 & $189 \pm 8$ & $265 \pm 50$ & $13 \pm 17$ & $199 \pm 80$ \\
& 270 & $188 \pm 6$ & $278 \pm 40$ & $13 \pm 11$ & $200 \pm 60$ \\
\hline & 30 & $154 \pm 50$ & $217 \pm 22$ & $70 \pm 50$ & $204 \pm 200$ \\
\hline Annealed at $850^{\circ} \mathrm{C}$ & 90 & $120 \pm 30$ & $209 \pm 3$ & $89 \pm 7$ & $199 \pm 20$ \\
& 270 & $119 \pm 13$ & $217 \pm 3$ & $80 \pm 4$ & $197 \pm 18$ \\
\hline
\end{tabular}

